\title{
ANOTHER LOOK AT SWEDISH BUSINESS \\ CYCLES, 1861-1988
}

\author{
Joakim Skalin \\ Timo Teräsvirta
}

Working Paper No. 130

November 1996 


\title{
ANOTHER LOOK AT SWEDISH BUSINESS CYCLES, 1861-1988
}

\author{
by \\ Joakim Skalin and Timo Teräsvirta \\ Department of Economic Statistics \\ Stockholm School of Economics \\ Box 6501, S-113 83 Stockholm, Sweden
}

First version: September 1996

This version: November 1996

\begin{abstract}
This paper considers nine long Swedish macroeconomic time series whose business cycle properties were discussed by Englund, Persson, and Svensson (1992) using frequency domain techniques. It is found by testing that all but two of the logarithmed and differenced series are nonlinear. The observed nonlinearity is characterized by STAR models. The statistical and dynamic properties of the estimated STAR models are investigated using, among other things, parametrically estimated 'local' or 'sliced' spectra. Cyclical variation at business cycle frequencies does not seem to be constant over time for all series, and it is difficult to find a 'Swedish business cycle'. Only two series may be regarded as having genuinely asymmetric cyclical variation. Standard Granger noncausality tests are adapted to the nonlinear (STAR) case, and the null hypothesis of noncausality is tested for pairs of series. The results point at strong temporal interactions between series. They also indicate that the assumption of functional form (linear or STAR) strongly affects the outcome of these pairwise tests.
\end{abstract}

Keywords. Granger causality; model spectrum; linearity test; time series model; nonlinearity; smooth transition autoregression

\section{JEL Classification Codes: C22, C53}

Acknowledgements. The first author gratefully acknowledges financial support from Jan Wallander's and Tom Hedelius' Foundation for Social Research and from the Swedish Council for Research in the Humanities and Social Sciences. The research of the second author was supported by the Swedish Council for Research in the Humanities and Social Sciences and Sonderforschungsbereich 373 at the Humboldt-Universität zu Berlin. Material from the paper has been presented at the Econometrics Days at Umeå universitet, May 1995, the Conference on Smoothing and Resampling in Economics at the Humboldt-Universität zu Berlin, October 1995, and in seminars at Freie Universität Berlin, Universidad Carlos III de Madrid, and GREQAM (Marseilles). Comments from participants in these events are gratefully acknowledged. Furthermore, we wish to thank Markku Rahiala for his many useful remarks and for generously allowing us to use his programme for numerical estimation of spectra of STAR models. The suggestions from Jürgen Wolters deserve special thanks. We are also grateful to John Hassler for providing us with the data. The responsibility of any errors and shortcomings in the paper remains ours.

Note: This paper will also appear in the discussion paper series 'Quantifikation und Simulation Ökonomischer Prozesse' of Humboldt-Universität zu Berlin. 


\section{INTRODUCTION}

In a recent paper, Englund, Persson and Svensson (1992), henceforth EPS, considered Swedish business cycles ('cyclical comovements between important macroeconomic variables with periods of around five years') using nine long Swedish macroeconomic

time series extending from 1861 to 1988 . First they defined business cycle variation as that found in the spectrum of a stationary series between frequencies corresponding to a cycle length (period) of 3 to 8 years. They filtered the series to achieve stationarity, estimated the spectral density and applied a band-pass filter (Priestley, 1981, p. 274275) to remove all variation at the frequencies other than those of interest. An inverse transformation was applied to transform the filtered series back to the time domain. Having done that, the authors computed contemporaneous correlations between the GDP and the other series and observed that most of them were positive. Real wages and productivity were contemporaneously uncorrelated with the GDP. Doing the same for moving subperiods indicated that the correlations were reasonably stable over time. EPS also computed the standard deviations of the filtered series over time and noted that the ratios of the standard deviations of the individual series to that of the GDP had been fairly constant over time. The main conclusion of EPS was that 'the Swedish business cycle seems to be uniform across very different epochs of Swedish economic history'.

Even after the findings of EPS, there are still interesting issues left to be considered using their macroeconomic data set. First, although EPS concluded that the Swedish 
business cycle has been uniform over time it also appears from the paper that the estimated spectra of the differenced logarithmic series at 'business cycle frequencies' corresponding to 3 to 8 years are not alike. The cyclical comovements appearing in the definition of business cycles thus do not seem to happen in complete harmony, and we would like to know more about differences between them. Second, the estimated spetra in EPS contain another interesting feature: a fairly marked peak at some frequency corresponding to a period longer than 10 years. EPS did not discuss it in any detail because it lies outside the band of business cycle frequencies. Nevertheless, its prominence makes it an interesting object of study. Third, there has been a lot of discussion of asymmetry of business cycles; see, for example, Mitchell (1927), Neftçi (1984), Stock (1987), Luukkonen and Teräsvirta (1991), Sichel (1993), and references therein. Our approach in this paper gives us an opportunity to consider the possible asymmetry in the Swedish business cycle. Finally, EPS did not consider temporal dynamic relationships between their variables because such an analysis was beyond the scope of the paper. Causal links between variables, such as the existence or otherwise of a driving variable for the cycle, are an interesting object of study. In this paper we investigate this aspect using Granger-causality as our econometric tool.

Long macroeconomic time series have been rather extensively analysed in the econometric literature. An interesting question to investigate has been if such long series have a unit root as opposed to the alternative that the series are stationary around a linear trend, see Nelson and Plosser (1982). When the alternative has been generalized to allow a single structural break in the trend at a known or unknown point (e.g. Perron, 1989, Raj, 1992, Zivot and Andrews, 1992) several unit root results 
have been reversed. For yet another alternative to the unit root hypothesis, see McCabe and Tremayne (1995).

The Swedish macroeconomic time series EPS considered are almost 130 years long and extend through a rather turbulent period in history. Allowing just a single break in a linear trend in 130 years seems a rather restrictive assumption. We therefore follow Teräsvirta (1995) by assuming that after taking first differences, the series are stationary and ergodic but may be nonlinear. This extension considerably increases the flexibility in modelling the series. Furthermore, nonlinearity does not seem an implausible assumption in view of all the dramatic events that have affected the Swedish economy such as the two world wars and the Great Depression of the 1930s. Although Sweden was not a belligerent country in these wars, it was and still is dependent on foreign trade. These events thus represented major exogenous shocks to the economy, and the response to those shocks may have been nonlinear. This can be checked by simply testing linearity against nonlinearity, and that is what we do. In cases where the null hypothesis is rejected we fit nonlinear models to the series, interpret the results, and compare the properties of the estimated models with each other.

The results indicate that most of the nine time series we consider are nonlinear. The estimated nonlinear models suggest that the dynamic properties of the series vary considerably from one series to the other. Granger noncausality tests indicate strong temporal links between many of the series. A detailed discussion follows below. 
The plan of the paper is as follows. Section 2 presents the data set. Section 3 considers our main econometric tool, the smooth transition autoregressive (STAR) model, and testing linearity against STAR. In Section 4 we report results of fitting STAR models to the data, interpret the estimated models and discuss our findings. Section 5 is devoted to testing Granger noncausality in a nonlinear framework and considering the results. Section 6 concludes.

\section{DATA}

The variables under study in this paper are the same as in EPS: gross domestic product, industrial production (value added in manufacturing and mining), private consumption, investment, exports, imports, employment (hours worked in manufacturing and mining), real wages, and productivity (industrial production divided by hours worked). For most of the variables, data is available for the period 1861-1988. The productivity and employment series start from 1870. Brief definitions of the variables and a discussion of the quality of the data are provided in EPS, whereas the raw data, detailed definitions and a description of the primary data sources can be found in Hassler, Lundvik, Persson and Söderlind (1992). ${ }^{1}$ The logarithmic series appear in Figure 2.1 and their first differences in Figure 2.2. All series have a positive trend, but the trend in employment levels off and starts bending downwards in the 1960s. Some series like exports and wages contain remarkably large

\footnotetext{
${ }^{1}$ Most of the series used in this paper have been taken directly from the data set in Hassler, Lundvik, Persson and Söderlind (1992). Some of the series have been computed by the present authors from the same raw data in accordance with the definitions provided in EPS and in appendix A in Hassler et al (1992).
} 
perturbations as seen from Figure 2.2. In general, the period between 1910 and 1950 has been more turbulent than the remaining parts in most of the series. An exception to this rule is the investment series in which the largest fluctuations occur in the beginning, from 1861 to 1875 . The industrial production also shows large fluctuations already in the 1880 s.

A brief characterization of the economic development during the period may be helpful in reading the graphs. The sample contains subperiods characterized by markedly different economic conditions. The years between 1875 and 1890 constitute a deflationary period between two cyclical peaks, with extensive layoffs and increased productivity. The First World War (associated with industrial growth until 1916, when the war restrained foreign trade) is followed by the 1920-1925 crisis (with a short but deep fall in employment) and a deep depression in 1929-1933. The expansion of the late thirties ends with the outbreak of the Second World War. The war leads to decreased private consumption and foreign trade but, on the other hand, many industries meet a relatively stable domestic demand. Finally, the stable growth during the 1950s and 1960s is succeeded by the oil crisis and slow growth in the 1970s. For a detailed description of the historical developments during the period, see, for example, Larsson (1993). 


\section{THE STAR MODEL AND LINEARITY TESTING}

\subsection{The model}

In this section we shall consider the possibility that the first differences of the logarithmic series are nonlinear. Furthermore, we assume that if this is the case these series can be adequately characterized by smooth transition autoregressive models. Our aim is to obtain a useful characterization of the dynamics of the series. We do not argue that this is the only way to model nonlinearity. For instance, one could consider nonparametric alternatives, although the series seem somewhat short for that provided the strong turbulence they have displayed. But the STAR family of models does have some useful properties. First, it is suitable for modelling series with asymmetric cyclical variations and turbulent periods; see for instance Teräsvirta and Anderson (1992) and Teräsvirta (1995). Second, the estimated, locally linear, models can be easily interpreted, which is an advantage. Finally, a modelling cycle consisting of the specification, estimation and evaluation stages already exists (Teräsvirta, 1994;

Eitrheim and Teräsvirta, 1996) and will be applied in this work.

A STAR model is defined as

$$
y_{t}=\pi_{10}+\pi_{1}^{\prime} w_{t}+\left(\pi_{20}+\pi_{2}^{\prime} w_{t}\right) F\left(y_{t-d}\right)+u_{t},
$$

where $\pi_{j}=\left(\pi_{j 1}, \mathrm{~K}, \pi_{j p}\right)^{\prime}, j=1,2, w_{t}=\left(y_{t-1}, \mathrm{~K} y_{t-p}\right)^{\prime}, u_{t} \sim \operatorname{nid}\left(0, \sigma_{u}^{2}\right)$. The transition 
function $F\left(y_{t-d}\right)$ is defined to be either a logistic function

$$
F\left(y_{t-d}\right)=\left(1+\exp \left\{-\gamma_{L}\left(y_{t-d}-c_{L}\right)\right\}\right)^{-1}, \gamma_{L}>0
$$

or an exponential function

$$
F\left(y_{t-d}\right)=1-\exp \left\{-\gamma_{E}\left(y_{t-d}-c_{E}\right)^{2}\right\}, \gamma_{E}>0
$$

Model (3.1) with transition function (3.2) will be referred to as a logistic STAR model of order $p, \operatorname{LSTAR}(p)$, whereas (3.1) with (3.3) is called an exponential STAR model of order $p, \operatorname{ESTAR}(p)$. It may be noted that other models, nonlinear as well as linear, appear as special cases of the STAR specifications. The LSTAR model approaches a two-regime threshold autoregressive model (see Tong, 1990) when $\gamma_{L} \rightarrow \infty$, since (3.2) in the limit is a step function of $y_{t-d}$ the value of which changes from zero to unity at $c_{L}$. When $\gamma_{L} \rightarrow 0$, the LSTAR model approaches a linear $\operatorname{AR}(p)$ model. Turning to the ESTAR model, equation (3.1) approaches a linear model both as $\gamma_{E} \rightarrow 0$ and (with probability one) as $\gamma_{E} \rightarrow \infty$. If $c_{E}=\pi_{20}=0$, the ESTAR model is identical to the exponential autoregressive model of Haggan and Ozaki (1981).

The role of the transition function in (3.1) is that it allows the coefficients for lagged values of $y_{t},\left[\pi_{1}+\pi_{2} F\left(y_{t-d}\right)\right]^{\prime}$, and the intercept, $\pi_{10}+\pi_{20} F\left(y_{t-d}\right)$, to change smoothly with $y_{t-d}$. This means that the local dynamics of the model change with $y_{t-d}$. This idea works differently for the two STAR models. The LSTAR model allows the 
local dynamics to be different for high and low values of the transition variable, $y_{t-d}$. The modelling of local dynamics as a function of a lagged value of $y$ makes it possible to model nonlinear effects of a shock. For instance, if a negative shock pushes a realization away from a locally stable regime ( $F$ close to unity, say), the subsequent change in the value of $F$ changes the local dynamics ( $F$ now close to zero, say). If this regime contains a pair of explosive complex roots, $y$ may be returned to the previous level a lot more quickly than would be the case if it followed a linear AR process.

In contrast to the LSTAR case, the ESTAR transition function is symmetric about $c_{E}$ in the sense that the local dynamics are the same for high as for low values of $y_{t-d}$, whereas the mid-range behaviour of the variable (values close to $c_{E}$ ) is different. (It should be noted that the mid-regime does not necessarily have to be locally stable.) For instance, with the exponential transition function, it is possible for $y$ to move rapidly between very small and very large values for which local dynamics are stable. We let the data decide which of the types of STAR models we fit to series for which linearity is rejected. Diagnostic tests will reveal whether a STAR model offers an adequate characterization of the data or not.

\subsection{Testing linearity}

The modelling cycle for building STAR models is discussed in Teräsvirta (1994) and Eitrheim and Teräsvirta (1996). Testing linearity against STAR constitutes the first step of the model specification stage. In order to do that one first selects a linear autoregressive model for the series with apparently no autocorrelation in the residuals. 
This can be done by applying an appropriate model selection criterion such as AIC. The selected model is the null model. For details of the test which has power against both LSTAR and ESTAR, see Teräsvirta (1994). The test is carried out for different values of the unknown delay parameter $d$, and the value of $d$ associated with the test with the smallest $p$-value is selected. If none of the $p$-values is sufficiently small, linearity is not rejected. Note that if testing linearity were the main point of the whole investigation we could assume $d$ unknown and carry out the test starting from that assumption as in Luukkonen, Saikkonen and Teräsvirta (1988). That way we would control the overall significance level of the test. In this paper model selection, including the choice of $d$, is an important part of the work. We therefore test linearity conditionally on $d$ and also use the results to select the delay.

A summary of the results of the tests can be found in Table 3.1. The table contains the maximum lag length of the autoregressive model, the smallest $p$-value of the tests, and the corresponding delay. It also contains the results of the model selection test sequence for choosing between ESTAR and LSTAR (see Teräsvirta, 1994) and the chosen model family. Linearity is usually rejected against STAR, and in many cases the rejection is extremely strong as the very low $p$-values indicate. The only exception is the GDP. The lag length AIC selects is two, and if that is applied in the tests, the minimum $p$-value is about 0.02 . If the lag length is increased to four, however, the evidence against linearity is weaker. We did estimate an LSTAR model for the GDP. In accordance with the test results the improvement in the fit compared to the linear model was small, and in the following we therefore treat the GDP as a linear process. The investment series is very turbulent in the beginning of the period. When we excluded the years 1861-1875 from the sample, the evidence against linearity 
practically vanished. Instead of trying to fit a STAR model just to accommodate those most distant observations we left them out and treated the remaining part of the series as linear. The other seven series were deemed nonlinear and STAR models were fitted to them. If the decision between the ESTAR and LSTAR was not clear-cut, both types of models were fitted to the data and the final decision was taken at the model evaluation stage.

\section{MODELLING THE SERIES AND INTERPRETING RESULTS}

\subsection{Evaluation of STAR models}

In this section we report results from the estimation of STAR models for five of the seven nonlinear series and the evaluation of the estimated models. Furthermore, we consider the dynamic properties of our models. For the two remaining series we just give a brief outline of the most interesting results. Our aim is to shed light on the cyclical properties of the series. Every estimated model is evaluated by a series of tests and we report results of these. (Table 4.1-4.3.) As usual, the assumption of no error autocorrelation should be tested. We use the Lagrange multiplier test Eitrheim and Teräsvirta (1996) derived for this purpose. Their paper also contains two other tests. One is for testing the hypothesis of no remaining nonlinearity. In this test the alternative hypothesis is that the data-generating process is an additive STAR model with two 'STAR components' instead of a single one as in (3.1). Finally, the constancy of the parameter vectors $\left(\pi_{j 0}, \pi_{j}^{\prime}\right)^{\prime}, j=1,2$, is tested against the hypothesis 
that the parameters change smoothly over time. Three tests are carried out. The first one, LM1, assumes that the parameters change monotonically over time, the second one, LM2, that the change is symmetric with respect to an unknown point in time, and the third one, LM3, that the change is possibly nonmonotonic but not necessarily symmetric. All the tests are carried out by auxiliary regressions. For details see Eitrheim and Teräsvirta (1996).

Each estimated STAR model equation is reported together with a number of statistics: AIC is the Akaike information criterion, SBIC is the Rissanen-Schwarz information criterion, $s$ is the estimated standard deviation of the residuals, LJB is the LomnickiJarque-Bera test of normality, LM is an LM statistic of no ARCH (Engle, 1982) based on two lags, and V.R. is the variance ratio $s^{2} / s_{A R}^{2}$, where $s_{A R}^{2}$ is the estimated variance of the residuals from the linear autoregressive model used as a basis for linearity testing. It gives an idea of the relative gain in the fit from applying a STAR model instead of a linear AR model. Numbers in parentheses following values of test statistics are $p$-values, whereas those below the coefficient estimates are asymptotic standard errors of the estimates. 


\subsection{Industrial production}

We first consider the industrial production which is an important component of GDP. The test sequence in Table 3.1 suggests an ESTAR model, and the final estimated model has the form

$$
\begin{aligned}
& y_{t}=2.87 y_{t-1}+1.30 y_{t-2}+2.00 y_{t-3}+0.41 y_{t-4}-0.89 y_{t-5}-0.56 y_{t-6} \\
& \begin{array}{lllll}
(1.44) & (0.62) & (1.38) & (0.40) & (0.40)
\end{array} \\
& +\left[0.073-2.87 y_{t-1}-1.30 y_{t-2}-2.25 y_{t-3}-0.41 y_{t-4}+0.89 y_{t-5}+0.56 y_{t-6}-0.30 y_{t-7}\right] \\
& \begin{array}{llllll}
(0.010) & (1.44) & (0.62) & (1.38) & (0.40) & (0.40)
\end{array} \\
& \times\left[1-\exp \left\{-1.82\left(y_{t-3}+0.089\right)^{2} / \nexists^{2}(y)\right\}\right]+\text { 唡 } \\
& \text { (0.63) } \quad(0.013)
\end{aligned}
$$

$s=0.065$

$\mathrm{LJB}=50\left(1 \times 10^{-11}\right)$

$\mathrm{LM}=0.14(0.87)$ skewness $=0.22$

$\mathrm{AIC}=-5.37$

V.R. $=0.85$ excess kurtosis $=3.1$

SBIC $=-5.11$

$R^{2}=0.23$.

The standardization of the exponent of $F$ by division by $\nexists^{2}(y)$, the sample variance of $y_{t}$, is introduced to make $\gamma$ scale-free and thus facilitate the interpretation of its estimate.

The maximum lag (seven) in (4.1) seems long but it should be pointed out that it is no different from that of the corresponding linear AR model. Table 4.1 contains results of the tests of no error autocorrelation. It is seen that the null hypothesis is not rejected. Table 4.2 has the results on the tests of no remaining nonlinearity. The tests are based on the third-order Taylor expansion of the second transition function; see Eitrheim and Teräsvirta (1996). The smallest $p$-value is 0.034 corresponding to a delay of $d=4$. Given the number of tests this is not very strong evidence against the model. The 
model passes the tests of parameter constancy when the constancy of all parameters is tested simultaneously. When the null hypothesis only concerns the nonlinear intercept and the other parameters are assumed constant even under the alternative, the result suggests that this intercept may not have been constant over time. This may have to do with the slowdown in the growth rate in the 1970s but it has not been followed up here.

The estimated equation (4.1) contains a number of parameter restrictions of the type $\pi_{1 j}=-\pi_{2 j}$. These restrictions exclude the 'combined parameter' $\pi_{1 j}+\pi_{2 j} F$ for $F=1$ and are supported by the data. (The restriction $\pi_{1 j}=0$ does the same for $F=0$.) The equation has a low location parameter value, $\epsilon_{E}=-0.089$, and Figure 4.3 shows the shape of the transition function. Every point indicates an observation so that one can readily see which values the transition function has obtained and how frequently. The same information ordered over time is found in Figure 4.2. The two figures together show that the transition function normally has been close to unity. It has moved further away from unity mainly in the 1880 s, from 1910 to early 1920 s, in the mid1930s, and in the early 1980s. Comparing the fit of the linear AR(7) model and the ESTAR model (4.1), see Figure 4.1, it is seen that the latter fits much better in the 1880 s and early 1920 s than the former. It also improves the explanation to the high growth rates following the depression in the early 1930s. We can conclude that the nonlinear model describes the most turbulent periods in the data better than the linear autoregressive model. The fit is not good for the last years of the sample for either of the two models. In fact, as already indicated, the rejection of the constancy of the intercept in the ESTAR model may have something to do with this. 
The dynamic behaviour of the model is characterized in two ways. Trying to interpret individual parameter estimates or the delay $d$ does not give much useful information ( $\not$ and $\vec{a}$ are the only exceptions). It is more instructive to compute the roots of the characteristic polynomial of (4.1) at given values of the transition function $F$ as in Teräsvirta (1994). The extreme values $F=0$ and $F=1$ are particularly interesting. The dominant roots of the characteristic polynomial of (4.1) given $F=0$ and $F=1$, respectively, can be found in Table 4.4. For $F=1$ (lowest and high values of the series), all roots are stationary. For $F=0$, there exists a real root which is greater than unity. It is needed to describe the sawtooth movements of the growth rate: it is not possible to explain this behaviour by a purely linear autoregressive model.

We could consider the situation for other values of $F$ but there exists another, more economic way of characterizing local dynamics. To this end, we define the 'local' or 'sliced' spectrum of the STAR model as follows:

$$
f_{y y}\left(\omega ; y_{t-d}\right)=(1 / 2 \pi)\left[\left\{1-\sum_{j=1}^{p}\left(\pi_{1 j}+\pi_{2 j} F\right) e^{-i j \omega}\right\}\left\{1-\sum_{j=1}^{p}\left(\pi_{1 j}+\pi_{2 j} F\right) e^{i j \omega}\right\}\right]^{-1}
$$

for $-\pi \leq \omega \leq \pi$, see, for example, Priestley (1981, section 4.12). As is seen from (4.2), this spectrum is a function of $F$ and thus of $y_{t-d}$. It is defined for those values of $F$ for which the roots of the lag polynomial $1-\sum_{j=1}^{p}\left(\pi_{1 j}+\pi_{2 j} F\right) B^{j}$ lie outside the unit circle, i.e., the estimated STAR model is locally stationary. Note that (4.2) is not standardized; integrated from zero to $\pi$, the function does not integrate to one. Thus the estimated local spectra have to be standardized to be comparable. Figure 4.4 
contains the standardized local spectra of model (4.1). In this figure, each curve represents a local spectrum and corresponds to a single observation of the transition variable. Most of these relate to values of $F$ close to unity, as Figures 4.2 and 4.3 already suggest. An interesting fact conveyed by Figure 4.4 is that there exists a local peak corresponding to a period of about 13-14 years. This peak is not very prominent for $F$ close to unity. It increases in size, however, when one moves away from $F=1$, and it can thus to a large extent be ascribed to the most turbulent periods in the data. For values of $F$ close to unity, a conspicuous (local) peak appears at 'business cycle frequencies' corresponding to a period length between 4 and 5 years. The peak is visible in every local spectrum appearing in the figure, which indicates that the corresponding cycle is an important underlying characteristic of the process. Another very distinct feature is the high-frequency tail of the spectrum due to large short-term swings in the growth rate.

The set of local spectra as defined in (4.2) thus can be used to illustrate the local dynamics of the estimated STAR model. However, it does not characterize the global dynamics of the model and should not be interpreted that way. Global dynamics are better illustrated by a 'model' spectrum; see Priestley (1981, pp. 268-9) for the linear case. Because the spectrum of a STAR model cannot be computed analytically, it is done by simulation ${ }^{1}$. The dominant peak in the model spectrum for industrial production in Figure 4.5 appears at a period of 13-14 years. Keeping in mind the information in Figure 4.4, this is another indication of the fact that nonlinearity in (4.1) characterizes the most turbulent periods in the data. Our conclusion thus is that

\footnotetext{
${ }^{1}$ For every STAR model, 99 realizations of 300 observations are generated using the estimated coefficients and a sequence of error terms, $u_{t} \sim \operatorname{nid}\left(0, s^{2}\right)$. The first 150 observations of each one of the
} 
there exists a distinct cyclical component in the industrial production series at the business cycle frequencies. The long 'cycle' is more of an artefact, because its appearance is just due to the most turbulent parts of the series and their timing.

Thus, in this case the traditional nonparametric sample spectrum, the STAR-based model spectrum, and the local spectra complete each other. In particular, the inspection of the local spectra together with the estimated transition function sheds light on the appearance of the 13-14-year cycle visible in the global spectral densities. 


\subsection{Exports}

We now turn to the exports series which has been strongly affected by events exogenous to the Swedish economy. As seen from Table 3.1, linearity is rejected very strongly. The model specification test sequence suggested $d=3$ and an LSTAR model. The estimated model is

$$
\begin{aligned}
& y_{t}=0.51 y_{t-1}-0.92 y_{t-2}-0.37 y_{t-3}+0.47 y_{t-4}-0.85 y_{t-5}-0.23 y_{t-6}-0.42 y_{t-7}+0.17 y_{t-9} \\
& \begin{array}{lllllll}
(0.18) & (0.23) & (0.14) & (0.15) & (0.22) & (0.077) & (0.17)
\end{array} \\
& +\left[0.05-0.51 y_{t-1}+1.13 y_{t-2}+0.27 y_{t-3}-0.47 y_{t-4}+0.85 y_{t-5}+0.42 y_{t-7}-0.098 y_{t-8}\right] \\
& \begin{array}{llllll}
(0.017) & (0.18) & (0.27) & (0.19) & (0.15) & (0.22)
\end{array} \\
& \times\left[1+\exp \left\{-6.79\left(y_{t-3}+0.047\right)\right\} / \partial(y)\right]^{-1}+\text { th }
\end{aligned}
$$

$s=0.099$

$$
\text { skewness }=-0.14
$$

excess kurtosis $=3.5$

$$
\mathrm{LJB}=61\left(6 \times 10^{-14}\right)
$$

$\mathrm{AIC}=-4.52$

$\mathrm{SBIC}=-4.19$

$\mathrm{LM}=0.30(0.74)$

V.R. $=0.65$

$R^{2}=0.48$

The estimated model does not seem to have autocorrelated errors (Table 4.1). On the other hand, (4.3) does not adequately characterize the nonlinearity in the data (Table 4.2). This may not be surprising given the irregularity of the series and the very strong rejection of linearity at the outset. The $p$-values of the tests of no remaining nonlinearity are at any rate remarkably higher than those of the linearity tests. Parameter constancy tests do not indicate any nonconstancy (Table 4.3).

Although model (4.3) does not account for all nonlinearity in the series we take a look at its properties. The transition function has varied most widely between 1900 and 1950. Compared with the linear model, the LSTAR model makes a contribution in explaining the developments during the first world war and the export boom following 
the second world war; see Figure 4.6. It also predicts a drop in the exports at the end of 1970s which did not occur. To understand the dynamic properties of (4.3) we begin with the roots of the characteristic polynomial as functions of $F$. From (4.3) we note that $\partial_{L}=-0.047$, and Figure 4.8 shows that the transition function gets close to zero roughly for $y_{t-3}<-0.1$. When $F=0$ there exist two pairs of explosive complex roots (Table 4.4). The corresponding period lengths are 4.4 and 9.3 years. For $F=1$, all roots are stationary, and the largest pair has the period 2.3 years. When $F$ decreases this root becomes real and strongly negative.

The model spectrum in Figure 4.10 is dominated by the 4 and 10.5 year peaks. However, from the local spectra in Figure 4.9, these peaks are seen to be mainly associated with relatively low values of the transition function, whereas the short-term dynamics dominate for transition function values close to unity. This information can be combined with that in Figure 4.7. This figure shows that the estimated transition function takes values close to unity much more frequently after than before 1950. It can thus be concluded that the cyclical fluctuations have not been constant over time. The 4 and 10.5 year peaks mainly characterize the earlier, more turbulent, period of the series. From 1950 onwards, short-run fluctuations (length of period less than 3 years) have dominated and there has been little business cycle variation to speak of. This does not necessarily show in the spectrum estimated from the whole sample, and the local and the global spectra thus again neatly complement each other. 


\subsection{Imports}

Imports are also greatly affected by exogenous events. Linearity is rejected extremely strongly against STAR (Table 3.1). The smallest $p$-value occurs at $d=1$, and the specification test sequence suggests an ESTAR model. The estimated model has the form

$$
\begin{aligned}
& y_{t}=0.57 y_{t-1}-0.42 y_{t-2}+0.29 y_{t-3}+0.19 y_{t-4}+0.15 y_{t-5}+0.37 y_{t-6} \\
& \begin{array}{lllll}
(0.19) & (0.080) & (0.093) & (0.072) & (0.11)
\end{array} \\
& +\left[-1.55 y_{t-1}-1.19 y_{t-3}-0.93 y_{t-5}-2.46 y_{t-6}-1.41 y_{t-7}\right] \\
& \begin{array}{lllll}
(0.34) & (0.33) \quad(0.31) \quad(0.46)
\end{array} \\
& \times\left[1-\exp \left\{-0.32\left(y_{t-1}-0.0030\right)^{2} / \partial^{2}(y)\right\}\right]+1 \mathrm{t} \\
& (0.17) \quad(0.016)
\end{aligned}
$$

$s=0.12$

$\mathrm{LJB}=94\left(5 \times 10^{-21}\right)$

$\mathrm{LM}=0.77(0.47)$

$$
\text { skewness }=-1.34
$$$$
\mathrm{AIC}=-4.17
$$$$
\text { V.R. }=0.51
$$

excess kurtosis $=3.4$

$\mathrm{SBIC}=-3.87$

$R^{2}=0.61$

There does not seem to be any autocorrelation in the errors (Table 4.1). The hypothesis of no remaining nonlinearity is rejected (Table 4.2). But, as in the case of the exports series, the $p$-values of the tests are a few magnitudes higher than in the linearity tests. The hypothesis of parameter stability cannot be rejected (Table 4.3). Thus we proceed to consider the properties of (4.4). However, there is a caveat: this inference is not valid because the model is not stable. We return to this point shortly.

Figure 4.11 indicates that the two world wars and their aftermaths constitute the most turbulent periods in the series. That is where the ESTAR model most contributes to the explanation, see Figure 4.12. In particular, it captures the extremely sharp peak in the growth rate when the second world war had ended. The roots of the characteristic 
polynomial in Table 4.4 reflect the very large fluctuations in the imports. It is perhaps not surprising that there exist several explosive roots for $F=1$. But there is also an explosive real root for $F=0$; the corresponding value of the transition variable $y_{t-1}$ is practically zero. This explosive band about zero is very narrow but enhances the sharpness of the fluctuations. The local spectra in Figure 4.14 accord well with the information in the roots. The dominating feature is the ridge representing the period of 4-5 years. As in the case of the industrial output, this 4-5 year cycle seems an important characteristic of the series. The estimation of the model spectrum failed because some of the simulated realizations diverged. This implies that (4.4) is not a stable model, which renders the standard statistical inference invalid. The model may thus be seen as a local (in time) approximation to the true data-generating process. Problems in finding a stable representation of imports have their root in the extremely large fluctuations in the growth rate of the series in connection with the two world wars.

\subsection{Employment}

The most distinguished features of this series can be seen from Figure 4.15. There was a large drop in the employment in the years following the first world war and another one followed by a rapid recovery in the 1930s. The second world war does not seem to have affected hours worked in manufacturing much. Linearity of the series is strongly rejected against STAR, the rejection being strongest when $d=1$. The model specification tests point at the ESTAR family, but an LSTAR model could also be considered a possibility. The estimated ESTAR model is 


$$
\begin{aligned}
& y_{t}=-0.98-3.53 y_{t-1}-9.65 y_{t-2}+6.16 y_{t-3}+3.52 y_{t-4} \\
& \text { (0.73) (2.25) (5.55) (5.26) (4.16) } \\
& +\left[1.01+3.53 y_{t-1}+9.65 y_{t-2}-6.16 y_{t-3}-3.52 y_{t-4}\right] \\
& \text { (0.73) (2.25) (5.55) (5.26) (4.16) } \\
& \times\left[1-\exp \left\{-0.32\left(y_{t-1}+0.17\right)^{2} / \mathcal{F}^{2}(y)\right\}\right]+\text { 用 }
\end{aligned}
$$

$s=0.038$

skewness $=-0.62$

excess kurtosis $=2.4$

$\mathrm{LJB}=36\left(2 \times 10^{-8}\right)$

$\mathrm{AIC}=-6.49$

SBIC $=-6.30$

$\mathrm{LM}=0.22(0.80)$

V.R. $=0.56$

$R^{2}=0.50$

The estimated coefficients of the longest lags seem insignificant but removing the lags has an adverse effect on the fit. There does not seem to be any error autocorrelation in the model (Table 4.1). It appears from Table 4.2 that (4.5) has captured almost all nonlinearity in the data. Some evidence of parameter instability exists (Table 4.3) but it is not very strong. An important thing to notice in (4.5) is that $\epsilon_{E}=-0.17$. Thus almost all observations belong to the right-hand tail of the transition function as is seen from Figure 4.17. The LSTAR model would thus do almost the same job as the ESTAR model (see Teräsvirta, 1994). We estimated such a model as well, but because the ESTAR model had a slightly better fit, it is reported here. Another special characteristic of (4.5) is that because of the parameter restrictions $\pi_{1 j}=-\pi_{2 j}$, $j=1, \ldots, 4$, the model is locally white noise with a positive mean $(0.03)$ when $F=1$. Figure 4.16 shows that values of the transition function have remained close to unity most of the time. The ESTAR model makes two major contributions. First, it explains the big decrease in employment in the beginning of the 1920s better than the linear AR model. Second, it tracks the data well from the mid-1960s onwards where the linear model fails. 
The characteristic polynomial for $F=0$ contains a pair of complex roots with a very large modulus. These roots remain explosive for considerably large values of $F$. The model spectrum (see Figure 4.19) has a broad peak corresponding to cycle length of 3.5 years and another peak at the zero frequency. Figure 4.18 depicting local spectra allows another view. For $F$ very close to unity the local spectrum is flat because the process is locally white noise with drift for $F=1$. A peak corresponding to the period of 3.5 years emerges rather quickly when $F$ decreases. Thus when employment has been growing (see Figure 4.15) at a steady rate, the series has shown little 'business cycle' or other regular cyclical variation. On the other hand, when the employment has been declining as from the 1960s onwards, very regular cyclical variation has appeared in the series. By combining the information in Figure 4.15 and in the graph of the transition function it can be concluded that the cyclical variation has been asymmetric. The troughs have had a tendency of being sharper than the peaks. The recovery of the growth rate from a deep trough has always been quick. In conclusion, whereas the series up to the 1960s displays little or no cyclical movements, roughly the last quarter of the century is characterized by a prominent asymmetric cycle with a rather short period. A steady 4-5 year 'business cycle' component is not a property of the employment series.

\subsection{Private consumption}

Figure 4.20 shows that the growth rate of the logarithmic private consumption fluctuates most in the 1910s due to the first world war. There is also a drop in the growth rate in the 1930s and another one followed by a rapid recovery in the early 
1940s. When linearity is tested against STAR it is rejected (Table 3.1). The model specification procedure indicated a slight preference for an LSTAR model, but it turned out that an ESTAR model had a somewhat better fit. It has the form

$$
\begin{aligned}
& y_{t}=0.033+0.36 y_{t-3}-0.71 y_{t-4}-0.23 y_{t-6} \\
& \begin{array}{llll}
(0.0081) & (0.15) \quad(0.14) \quad(0.12)
\end{array} \\
& +\left[-0.016+0.21 y_{t-1}-0.20 y_{t-2}-0.36 y_{t-3}+1.28 y_{t-4}-0.44 y_{t-5}+0.23 y_{t-6}+0.29 y_{t-9}\right] \\
& \begin{array}{llllll}
(0.013) & (0.091) & (0.091) & (0.15) & (0.20) & (0.11)
\end{array} \\
& \times\left[1-\exp \left\{-1.67\left(y_{t-1}-0.059\right)^{2} / \partial^{2}(y)\right\}\right]+\text { 开 } \\
& \text { (0.52) (0.0041) }
\end{aligned}
$$

$s=0.032$

$\mathrm{LJB}=3(0.3)$

$\mathrm{LM}=2.66(0.08)$ skewness $=-0.36$

$\mathrm{AIC}=-6.78$

V.R. $=0.79$ excess kurtosis $=0.2$

$\mathrm{SBIC}=-6.50$

$R^{2}=0.44$

Model (4.6) is the only model whose residuals do not contain outliers (the LomnickiJarque-Bera test does not reject the normality assumption). There is no error autocorrelation, but the model does not adequately describe all the nonlinearity. However, the $p$-values of the tests are a few magnitudes higher than those of the linearity tests, and the residual variance is just $4 / 5$ of that of the linear model. No stability test rejects parameter constancy. The model is also different from the preceding ones in the sense that while it fits better than the linear one, the fit of (4.6) is not vastly superior to that of the AR model anywhere in the sample. This can be seen from Figure 4.20. Figure 4.21 indicates that the transition function fluctuates between zero and one during the whole sample period. Thus, unlike all the other series considered here the consumption series seems inherently nonlinear. Model (4.6) is locally stationary everywhere. There is a complex pair of roots with modulus 0.99 and 
period 2.7 years and another one with modulus 0.91 and period 9.8 years at $F=0$ (for this value, $\left.\partial_{E}=0.06\right)$.

The model spectrum in Figure 4.24 has a large and flat peak at a frequency corresponding to a period of 3 to 4 years, but there is also a very distinct 10 -year peak. The local spectra in Figure 4.23 are interesting. At values of $F$ close to unity there exists a strong peak at the cycle length of about 4 years. When $F$ decreases this peak moves to the right. This indicates a certain asymmetry: at high rates of growth (around 6 per cent) the cyclical fluctuations tend to be more peaked than at lower rates of growth. This asymmetry accords well with the flat peak of the model spectrum. A univariate analysis does not provide an explanation to asymmetric cyclical behaviour of consumption: it merely establishes the fact.

When $F$ approaches zero, a 10-year peak visible for all values of $F$ grows stronger. This peak seems mainly due to the distance between the end of the World War I turbulence and the Great Depression on the one hand, and that between this recession and the effects of World War II on consumption on the other. Its emergence can also be expected from the roots of the characteristic polynomial for $F=0$ discussed above. Again, the same peak appeared in the model spectrum. Thus, also for this apparently inherently nonlinear series, the information in the model spectrum can be usefully completed by the set of estimated sliced spectra. 


\subsection{Other series}

The other two series modelled by STAR models are productivity and wages. The productivity series is industrial production divided by employment, and the estimated model shares characteristics of the employment model. For this series, the rejection of linearity is not overwhelming $\left(p_{\min }=0.0248\right)$. We do not report the estimated model, but Figure 4.26 shows local spectra. The local spectrum is completely flat for $F=1$, and a peak at the cycle length 4 years emerges as $F$ decreases. Figure 4.25 shows that the model fit is not good everywhere. The substantial productivity increases after the first world war remain unexplained. This was mainly due to a rapid fall in employment. On the other hand, the turbulence of the 1880s due to large fluctuations in the industrial production is captured reasonably well. Furthermore, the test of no additive nonlinearity indicates that the model does pick up all nonlinearity there is in the data.

Linearity is rejected very strongly for the wages series. The estimated LSTAR model explains a part of the turbulence due to the first world war, see Figures 4.27 and 4.28. The transition function differs from unity only on two occasions. However, the test of no remaining nonlinearity reveals that the STAR model gives a far from adequate description of the data. We have thus not pursued this model any further. Detailed modelling results for the wages series are available from the authors upon request. 


\subsection{Linear series}

As seen from Table 3.1, there is not much evidence against linearity in the GDP series. The same is true for the investment series after omitting the first 15 observations. We have nevertheless computed model spectra for both series, see Figures 4.29 and 4.30. Because of linearity, this can be done by assuming $F \equiv 0$ and applying (4.2). It is seen that the cyclical variation parametrized by an AR(4) model is not strong. The spectrum has a rather broad peak at a frequency corresponding to the period of about 3 years. The AR model for investment suggests that the most prominent feature in the data, ignoring the years $1861-1875$, is a cycle with a period of about 6 years.

\subsection{Business cycle fluctuations, asymmetries, and the adequacy of the STAR models}

One of the purposes of this paper has been to complete the findings of EPS on the characteristics of the Swedish business cycle. Our results indicate that two of the series we investigated, industrial production and imports, contain fluctuations at business cycle frequencies corresponding to a period of 4-5 years. Consumption, the only inherently nonlinear process among the ones considered, also shows fluctuations within the 3-8 year band, but their frequency is higher (period 3-4 years). For exports and employment, the business cycle is a somewhat elusive concept. The exports series shows cyclical variation before 1950 but since then, short-term variation has been dominant in the series. Early in the period, employment has shown strong steady 
growth interrupted by occasional collapses of the growth rate. Regular 'business cycle variation' (period 3.5 years) has appeared only in the descending part of the series, from 1960s onwards. Of the linear series, investment seems to have a six-year cyclical component. For the GDP, the evidence of a regular cyclical component is weak. The techniques we have applied thus yield a somewhat more detailed picture of the cyclical variation in long Swedish macroeconomic series than that of EPS.

As noted above, linearity is strongly rejected for many of the series. This does not, however, automatically imply asymmetry. In fact, our considerations suggest that observed nonlinearity is mainly due to the large exogenous shocks the Swedish economy has been subjected to during the last 130 years. Consumption appears to be one variable whose growth rate is inherently nonlinear and whose cyclical fluctuations show signs of asymmetry. In this case, troughs on the average are sharper than peaks, except for some very extreme peaks. Another one is employment. While the cyclical frequency is constant over values of $F$, the peak in the spectrum grows in importance for descending values of $F$. This indicates that troughs even in this case are sharper than peaks.

As a summary, STAR models offer a reasonable explanation to fluctuations in three series out of seven: industrial production, employment, and productivity. They explain some but not all of the movements in the most turbulent periods in consumption, exports, and imports. At least for exports and imports, which have been directly subject to a few very large shocks, one might consider an outlier approach as in Balke and Fomby (1994) or van Dijk, Franses and Lucas (1996). The same consideration 
applies to the wages series whose dynamic behaviour a STAR model has not been able to capture.

\section{TESTING THE NONCAUSALITY HYPOTHESIS}

\subsection{General}

So far the focus has been on cyclical properties of the univariate series. It would also be interesting to consider temporal relationships between them. For instance, it would be interesting to know whether or not there is a driving variable behind the cyclical variation and what kind of dynamic interactions there may have existed between the variables. In this study, the number of variables is relatively large (nine) whereas the sample size is only moderate (less than 130 observations). This fact combined with strong observed nonlinearities make a system approach to these problems a less feasible alternative. A more modest beginning may be made by investigating pairwise causal relationships between variables. This is normally done by testing the null hypothesis of Granger noncausality (Granger, 1969) between two variables. There is a large literature on this topic; see Geweke (1984) for a survey. However, most of the testing is carried out in a completely linear framework. More recently, Baek and Brock (1992), Hiemstra and Jones (1994), and Bell, Kay and Malley (1996), proposed nonparametric tests of noncausality. 
The linear framework is not applicable in our case because most of our Swedish macroenonomic series are nonlinear. On the other hand, because we have already constructed parametric nonlinear STAR models for our variables it appears natural to continue using parametric tests. Such tests do not seem to exist for nonlinear series but below we are going to propose one based on smooth transition regression (STR) and apply it to our series. This also gives us an opportunity to compare the results with what one obtains by ignoring nonlinearity and applying corresponding tests based on linear equations to the same series.

\subsection{An STR-based test of Granger-noncausality}

A simple way of testing the null hypothesis that an observed series $x_{t}$ does not

(linearly) Granger cause another series, $y_{t}$, in a single-equation framework is to test the null hypothesis $\beta_{1}=\ldots=\beta_{q^{*}}=0$ in

$$
y_{t}=\theta+\alpha_{1} y_{t-1}+\mathrm{K}+\alpha_{p^{*}} y_{t-p^{*}}+\beta_{1} x_{t-1}+\mathrm{K}+\beta_{q^{*}} x_{t-q^{*}}+\varepsilon_{t}
$$

where $\varepsilon_{t} \sim \operatorname{iid}\left(0, \sigma_{\varepsilon}^{2}\right)$ under $H_{0}$. Analogously when $y_{t}$ (under the null hypothesis of noncausality) is generated by the STAR model (3.1), we may perform a noncausality test by testing a null hypothesis of non-existent predictive power of lagged values of another variable, $x_{t}$. The sequence $\left\{x_{t}\right\}$ is assumed to be stationary and ergodic. The nonlinear impact of $x$ on $y$ is characterized by an additive smooth transition 
component. Consider the following additive smooth transition regression model

$$
y_{t}=\pi_{10}+\pi_{1}^{\prime} w_{t}+\left(\pi_{20}+\pi_{2}^{\prime} w_{t}\right) F\left(y_{t-d}\right)+\delta_{1}^{\prime} v_{t}+\left(\delta_{20}+\delta_{2}^{\prime} v_{t}\right) G\left(x_{t-e}\right)+u_{t}
$$

where $\delta_{j}=\left(\delta_{j 1}, \mathrm{~K}, \delta_{j q}\right)^{\prime}, j=1,2, v_{t}=\left(x_{t-1}, \mathrm{~K} x_{t-q}\right)^{\prime}, G(\cdot)$ is a transition function similar to the ones defined in (3.2-3.3), and $e$ is an unknown delay. The noncausality hypothesis is $H_{0}: G \equiv 0$ and $\delta_{1 i}=0, i=1, \mathrm{~K} q$. Furthermore, we assume that under $H_{0}$, $u_{t} \sim \operatorname{nid}\left(0, \sigma_{u}^{2}\right)$, and that the parameters of (5.2) can be consistently estimated by nonlinear least squares under this null hypothesis.

The test is a modification of the test of no additive nonlinearity in Eitrheim and Teräsvirta (1996). The identification problem due to the fact that (5.2) is not identified under $H_{0}$ is again circumvented by approximating the second transition function $G$ by its Taylor approximation. However, in this case we want to control the overall significance level of the test while retaining the assumption that the delay $e$ is unknown. This can be achieved by proceeding as in Luukkonen, Saikkonen and Teräsvirta (1988). Doing that and choosing the 'economy version' (S3) of their test, the relevant approximation to (5.2) has the form

$$
y_{t}=\tilde{\pi}_{10}+\pi_{1}^{\prime} w_{t}+\left(\pi_{20}+\pi_{2}^{\prime} w_{t}\right) F\left(y_{t-d}\right)+\kappa^{\prime} v_{t}+\sum_{i=1}^{q} \sum_{j=i}^{q} \phi_{i j} x_{t-i} x_{t-j}+\sum_{i=1}^{q} \psi_{i} x_{t-i}^{3}+r_{t}
$$

where $\kappa=\left(\kappa_{1}, \mathrm{~K} \kappa_{q}\right)^{\prime}$. The null hypothesis is $H_{0}: \kappa_{i}=0, \phi_{i j}=0, \psi_{i}=0, i=1, \ldots, q$, $j=i, \ldots, q$. Under $H_{0}, r_{t}=u_{t}$ and the resulting test statistic has an asymptotic $\chi^{2}-$ 
distribution with $q(q+1) / 2+2 q$ degrees of freedom, assuming that all necessary moments and cross-moments exist. The test may be carried out by regressing the residuals from (5.2) estimated under the null hypothesis on the gradient vector of the null model, $x_{t-i}, i=1, \ldots, q, x_{t-i} x_{t-j}, i=1, \ldots, q, j=i, \ldots, q$, and $x_{t-i}^{3}, i=1, \ldots, q$. The degrees of freedom in the numerator of the $F$-variant of the test are $q(q+1) / 2+2 q$ and in the denominator $T-n-q(q+1) / 2-2 q$ where $n$ is the dimension of the gradient vector. The test may be carried out in the same way even if $\left\{y_{t}\right\}$ is a linear sequence. The only modification is that $F \equiv 0$ in (5.2).

The size of the test in samples like ours may be a cause of worry. Because of rather long lags, the number of degrees of freedom in the numerator in some of our tests is rather large relative to that in the denominator of the statistic which might cause size distortion. We carried out a small simulation study (details available from the authors) to check this possibility but did not find any cause for concern.

One may feel that the assumption that the second additive component in (5.2) is of STR type is unduly restrictive. The more general approach, not assuming a particular functional form for this component as discussed in Eitrheim and Teräsvirta (1996), can be adapted to this situation without problems. For large $q$, however, the dimension of the null hypothesis may be so large that in small samples it often leads to a substantial loss of power. 


\subsection{Results}

Table 5.1 contains the results from the nonlinear tests of Granger-noncausality. The tests are based on the STAR models of section 4 for all variables except GDP and investments. To obtain an idea of the effect of the lag length on the results, the tests were performed for $q=5, \ldots, 10$ in (5.2). Interpreting the results requires care because a rejection of the null hypothesis does not imply a direct causal link between a pair of variables. The tests are bivariate, and changing the information set may change conclusions. Nevertheless, the STR-based tests suggest a large number of interactions between the variables. In particular, employment and productivity are strongly linked with a majority of the other variables. The results may not directly point out a driving variable although industrial production is much more often a causing than a caused variable. Another conspicuous observation is that the variables representing links between the Swedish economy and the rest of the world, exports and imports, appear clearly more often as causing than caused variables. (Between the two, exports seem to Granger-cause imports rather than the other way round. Also note that the model of imports was not stable so that the $p$-values are just indicative.) In particular, causality running from these variables (but also from consumption) to wages is very strong. This is in accord with Sweden being a small open economy dependent on foreign trade. On the other hand, industrial production has a role similar to imports and exports. Finally, one should note that the analysis focuses on short-run connections between the series. Possible long-run relationships between the Swedish macroeconomic variables are not discussed here. 
For comparison, the noncausality hypothesis was also tested linearly using (5.1). The results can be found in Table 5.2. Comparing them with those in Table 5.1, the outcomes of the two forms of noncausality tests are seen to differ in a number of ways. In some cases, the nonlinear test indicates two-way causality between variables where the linear test finds no causality in any direction or one-way causality. In other cases, the direction of causality may differ between the two tests.

A general observation is that the linear tests find much less causal links between the series than the nonlinear tests do. The employment and productivity series serve as illustrative examples. According to the STR-based test they are linked with almost all the other series. The linear tests suggest both fewer and weaker links. The industrial production also is remarkably weakly linked together with the other variables. A general conclusion is that assumptions concerning the functional form play an important role in testing the null hypothesis of Granger noncausality.

\section{CONCLUSIONS}

The results of the paper show that behind the uniform business cycle EPS found by analysing long Swedish macroeconomic time series there is plenty of individual behaviour in the series. Some series such as GDP show only weak cyclical behaviour. In some other ones cyclical variation is elusive, sometimes it may be present, sometimes not. For series with relatively strong cyclical components the 'business cycle frequencies' with peaks in the spectra are not necessarily the same. In some 
series, cyclical variation seems asymmetric, in others it does not. It seems that the sometimes strong peaks in the spectra of these series at low frequencies can be ascribed to rather few exceptional observations or periods in the series.

Our study also indicates that there are plenty of temporal links between the variables. There may not exist a clear driving variable among the ones considered, industrial production being the closest candidate. On the other hand we are able to demonstrate the fact that the functional form strongly affects the results of Granger noncausality tests. That this may be the case is well known, see, for example, the discussion in Hendry (1995, p. 175-176), but empirical examples of this phenomenon have not been many.

Finally, we may conclude that STAR models are useful alternatives to linear models as research tools in this work. Although we have not been able to find an adequate STAR representation for every nonlinear series, the STAR models we have fitted to the data give us plenty of insight into characteristic features of the long Swedish macroeconomic time series we consider. With their help, we have been able to complete and enrich the analysis and conclusions of EPS on the many properties of Swedish business cycles from 1860s to late 1980s. 


\section{References}

Baek, E. G., and W. A. Brock (1992). A general test for nonlinear Granger causality: bivariate model. Unpublished manuscript.

Balke, N. S., and T. B. Fomby (1994). Large shocks, small shocks, and economic fluctuations: outliers in macroeconomic time series. Journal of Applied Econometrics, 9, 181-200.

Bell, D., J. Kay, and J. Malley (1996). A nonparametric approach to nonlinear causality testing. Economics Letters, 51, 7-18.

van Dijk, D., P. H. Franses, and A. Lucas (1996). Testing for smooth transition nonlinearity in the presence of outliers. Erasmus University Rotterdam, Econometric Institute Report 9622/A.

Eitrheim, Ø., and T. Teräsvirta (1996). Testing the adequacy of smooth transition autoregressive models. Journal of Econometrics, 74, 59-75.

Engle, R. F. (1982). Autoregressive conditional heteroskedasticity with estimates of the variance of United Kingdom inflation. Journal of Monetary Economics, 30, 987-1007.

Englund, P., T. Persson, and L. E. O. Svensson (1992). Swedish business cycles: 1861-1988. Journal of Monetary Economics, 30, 343-371.

Geweke, J. (1984). Inference and causality in economic time series models. In: Z. Griliches and M. D. Intriligator (eds.). Handbook of Econometrics, Vol. 2, 11011144. Amsterdam: North-Holland.

Granger, C. W. J. (1969). Investigating causal relations by econometric models and cross-spectral methods. Econometrica, 37, 428-438.

Haggan, V., and T. Ozaki (1981). Modelling nonlinear random vibrations using an amplitude-dependent autoregressive time series model. Biometrika, 68, 189-196.

Hassler, J., P. Lundvik, T. Persson, and P. Söderlind (1992). The Swedish business cycle: stylized facts over 130 years. Monograph series, 21, Institute for International Economic Studies, Stockholm University.

Hendry, D. F. (1995). Dynamic econometrics. Oxford: Oxford University Press.

Hiemstra, C., and J. D. Jones (1994). Testing for linear and nonlinear Granger causality in the stock price-volume relation. Journal of Finance, 49, 1639-1664.

Larsson, M. (1993). En svensk ekonomisk historia 1850-1985, 2nd ed. Stockholm: SNS förlag.

Luukkonen, R., and T. Teräsvirta (1991). Testing linearity of economic time series against cyclical asymmetry. Annales d'économie et de statistique, 20/21, 125-142.

Luukkonen, R., P. Saikkonen, and T. Teräsvirta (1988). Testing linearity against smooth transition autoregressive models. Biometrika, 75, 491-499.

McCabe, B. P. M., and A. R. Tremayne (1995). Testing a time series for difference stationarity. Annals of Statistics, 23, 1015-1028. 
Mitchell, W. C. (1927). Business cycles: the problem and its setting. New York: National Bureau of Economic Research.

Neftçi, S. (1984). Are economic time series asymmetric over the business cycle? Journal of Political Economy, 92, 307-308.

Nelson, C. R., and C. I. Plosser (1982). Trends and random walks in macroeconomic time series: some evidence and implications. Journal of Monetary Economics, 10, 139-162.

Perron, P. (1989). The great crash, the oil price shock, and the unit root hypothesis. Econometrica, 57, 1361-1401.

Priestley, M. B. (1981). Spectral analysis and time series. New York: Academic Press.

Raj, B. (1992). International evidence on persistence in output in the presence of an episodic change. Journal of Applied Econometrics, 7, 281-293.

Sichel, D. E. (1993). Business cycle asymmetry: a deeper look. Economic Inquiry, 31, 224-236.

Stock, J. (1987). Measuring business cycle time. Journal of Political Economy, 95, 1240-1261.

Teräsvirta, T. (1994). Specification, estimation, and evaluation of smooth transition autoregressive models. Journal of the American Statistical Association, 89, 208218.

Teräsvirta, T. (1995). Modelling nonlinearity in U.S. gross national product 18891987. Empirical Economics, 20, 577-597.

Teräsvirta, T., and H. Anderson (1992). Characterizing nonlinearities in business cycles using smooth transition autoregressive models. Journal of Applied Econometrics, 7, S119-S136.

Tong, H. (1990). Non-linear time series: a dynamical system approach. Oxford: Oxford University Press.

Zivot, E., and D. W. K. Andrews (1992). Further evidence on the great crash, the oilprice shock, and the unit-root hypothesis. Journal of Business and Economic Statistics, 10, 251-270. 


\section{TABLES}

Table 3.1

Results of linearity tests: number of lags in the linear AR model $(p)$, minimum $p$-value $\left(\min \left[p_{F_{L}}\right]\right)$ over delays $d=1, \ldots, p$; corresponding delay $(d), p$-values of the tests in the model selection sequence $\left(p_{F_{4}}\right.$, $\left.p_{F_{3}}, p_{F_{2}}\right)$, the selected model family $(\mathrm{E}=\mathrm{ESTAR}, \mathrm{L}=\mathrm{LSTAR})$.

\begin{tabular}{|c|c|c|c|c|c|c|c|}
\hline Variable & $p$ & $\min \left[p_{F_{L}}\right]$ & $d$ & $p_{F_{4}}$ & $p_{F_{3}}$ & $p_{F_{2}}$ & STAR \\
\hline Industrial production & 7 & 0.031 & 3 & 0.070 & 0.028 & 0.63 & $\mathrm{E}$ \\
\hline Imports & 7 & $2.1 \times 10^{-13}$ & 1 & 0.026 & $7.7 \times 10^{-10}$ & $6.74 \times 10^{-6}$ & $\mathrm{E}$ \\
\hline Exports & 9 & $2.1 \times 10^{-8}$ & 3 & 0.00025 & 0.0039 & 0.00013 & $\mathrm{~L}$ \\
\hline Productivity & 2 & 0.025 & 1 & 0.045 & 0.036 & 0.47 & $\mathrm{E}$ \\
\hline Real wage & 4 & $2.7 \times 10^{-10}$ & 1 & $1.4 \times 10^{-6}$ & $6.9 \times 10^{-5}$ & 0.013 & $\mathrm{~L}$ \\
\hline Investments & 4 & $1.8 \times 10^{-7}$ & 1 & 0.0061 & 0.00027 & 0.00062 & $\mathrm{~L}$ \\
\hline Consumption & 9 & $4.2 \times 10^{-5}$ & 1 & 0.0030 & 0.0048 & 0.054 & $\mathrm{E}$ \\
\hline \multirow[t]{2}{*}{ GDP } & 2 & 0.019 & 2 & 0.0017 & 0.64 & 0.54 & $\mathrm{~L}$ \\
\hline & 4 & 0.065 & & & & & \\
\hline Employment & 4 & $3.2 \times 10^{-10}$ & 1 & 0.0050 & $6.26 \times 10^{-6}$ & $2.8 \times 10^{-5}$ & $\mathrm{E}$ \\
\hline
\end{tabular}

Note: For details of the test sequence for choosing between ESTAR and LSTAR models see Teräsvirta (1994).

Table 4.1

$p$-values of LM tests of no error autocorrelation.

\begin{tabular}{lllllllll}
\hline Variable & \multicolumn{2}{l}{ Number of lags } \\
& 1 & 2 & 3 & 4 & 5 & 6 & 7 & 8 \\
\hline Industrial production & 0.70 & 0.91 & 0.98 & 0.94 & 0.97 & 0.49 & 0.23 & 0.28 \\
Imports & 0.22 & 0.49 & 0.44 & 0.32 & 0.11 & 0.12 & 0.10 & 0.091 \\
Exports & 0.66 & 0.56 & 0.68 & 0.75 & 0.47 & 0.49 & 0.61 & 0.68 \\
Productivity & 0.77 & 0.93 & 0.96 & 0.99 & 0.92 & 0.96 & 0.68 & 0.37 \\
Real wage & 0.23 & 0.32 & 0.46 & 0.59 & 0.72 & 0.82 & 0.88 & 0.61 \\
Consumption & 0.40 & 0.54 & 0.69 & 0.82 & 0.93 & 0.95 & 0.93 & 0.96 \\
Employment & 0.22 & 0.069 & 0.091 & 0.069 & 0.084 & 0.18 & 0.38 & 0.37 \\
\hline
\end{tabular}

Note: For details of the test see Eitrheim and Teräsvirta (1996). 
Table 4.2

$p$-values of tests of no remaining nonlinearity.

\begin{tabular}{llllllllll}
\hline Variable & Delay & & & & & & & \\
& 1 & 2 & 3 & 4 & 5 & 6 & 7 & 8 & 9 \\
\hline Ind. prod. & 0.10 & 0.33 & 0.22 & 0.034 & 0.84 & 0.14 & 0.15 & & \\
Imports & 0.0057 & 0.0027 & 0.0021 & 0.030 & 0.14 & 0.72 & 0.11 & & \\
Exports & 0.00094 & 0.00053 & 0.028 & $6.1 \times 10^{-5}$ & 0.0052 & 0.0031 & 0.0038 & 0.0055 & 0.026 \\
Productivity & 0.15 & 0.76 & & & & & & & \\
Real wage & $7.7 \times 10^{-9}$ & 0.00032 & $9.0 \times 10^{-5}$ & 0.024 & & & & & \\
Consumption & 0.0083 & 0.019 & 0.057 & 0.082 & 0.053 & 0.087 & 0.53 & 0.092 & 0.24 \\
Employment & 0.40 & 0.035 & 0.30 & 0.072 & & & & & \\
\hline
\end{tabular}

Note: The tests are based on the third-order Taylor expansion of the second transition function; for details see Eitrheim and Teräsvirta (1996).

Table 4.3

$p$-values of LM tests of parameter constancy: $L M_{1}, L M_{2}, L M_{3}(F$ tests).

\begin{tabular}{lllll}
\hline Variable & Parameters & $L M_{1}$ & $L M_{2}$ & $L M_{3}$ \\
\hline Industrial production & Intercepts and lags & 0.41 & 0.41 & 0.82 \\
production & Intercepts only & 0.016 & 0.033 & 0.066 \\
\hline Imports & Intercepts and lags & 0.58 & 0.44 & 0.47 \\
\hline Exports & Intercepts and lags & 0.94 & 0.61 & 0.28 \\
& Intercepts only & 0.72 & 0.92 & 0.98 \\
\hline Productivity & Intercepts and lags & 0.049 & 0.13 & 0.31 \\
& Intercepts only & 0.80 & 0.26 & 0.50 \\
\hline Consumption & Intercepts and lags & 0.23 & 0.34 & 0.45 \\
& Intercepts only & 0.47 & 0.81 & 0.59 \\
\hline Employment & Intercepts and lags & 0.31 & 0.029 & 0.049 \\
& Intercepts only & 0.28 & 0.10 & 0.15 \\
\hline
\end{tabular}

Note: For details of the test see Eitrheim and Teräsvirta (1996). 
Table 4.4

Roots of characteristic polynomials for various values of the transition function $F$.

Only roots with modulus $\geq 0.90$ are displayed.

\begin{tabular}{|c|c|c|c|c|c|c|}
\hline \multirow{4}{*}{$\begin{array}{l}\text { Industrial } \\
\text { production } \\
\text { (ESTAR) }\end{array}$} & \multicolumn{3}{|l|}{ Mid-regime $(F=0)$} & \multicolumn{3}{|l|}{ Outer regime $(F=1)$} \\
\hline & Root & $\begin{array}{l}\text { Modulus } \\
\text { (half-life) }\end{array}$ & Period & Root & $\begin{array}{l}\text { Modulus } \\
\text { (half-life) }\end{array}$ & Period \\
\hline & 3.42 & 3.42 & & -0.90 & 0.90 & \\
\hline & $-0.10 \pm 0.91 i$ & $0.92(8.9)$ & 3.7 & & & \\
\hline \multirow{5}{*}{$\begin{array}{l}\text { Imports } \\
\text { (ESTAR) }\end{array}$} & \multicolumn{3}{|l|}{ Mid-regime $(F=0)$} & \multicolumn{3}{|l|}{ Outer regime $(F=1)$} \\
\hline & Root & $\begin{array}{l}\text { Modulus } \\
\text { (half-life) }\end{array}$ & Period & Root & $\begin{array}{l}\text { Modulus } \\
\text { (half-life) }\end{array}$ & Period \\
\hline & $0.38 \pm 0.811 i$ & $0.90(7.2)$ & 5.5 & $0.89 \pm 0.64 i$ & 1.09 & 10.0 \\
\hline & 1.04 & 1.04 & & $-0.05 \pm 1.19 i$ & 1.19 & 3.9 \\
\hline & & & & -1.29 & 1.29 & \\
\hline \multirow{5}{*}{$\begin{array}{l}\text { Exports } \\
\text { (LSTAR) }\end{array}$} & \multicolumn{3}{|l|}{ Lower regime $(F=0)$} & \multicolumn{3}{|l|}{ Upper regime $(F=1)$} \\
\hline & Root & $\begin{array}{l}\text { Modulus } \\
\text { (half-life) }\end{array}$ & Period & Root & $\begin{array}{l}\text { Modulus } \\
\text { (half-life) }\end{array}$ & Period \\
\hline & $0.17 \pm 1.142 i$ & 1.16 & 4.4 & $-0.86 \pm 0.33 i$ & $0.92(9.4)$ & 2.3 \\
\hline & $0.79 \pm 0.632 i$ & 1.01 & 9.3 & & & \\
\hline & -0.90 & 0.90 & & & & \\
\hline \multirow{3}{*}{$\begin{array}{l}\text { Productivity } \\
\text { (ESTAR) }\end{array}$} & \multicolumn{6}{|l|}{ Mid-regime $(F=0)$} \\
\hline & Root & Modulus & Period & & & \\
\hline & $0 \pm 1.69 i$ & 1.69 & 4 & & & \\
\hline \multirow{4}{*}{$\begin{array}{l}\text { Consumption } \\
\text { (ESTAR) }\end{array}$} & \multicolumn{3}{|l|}{ Mid-regime $(F=0)$} & \multicolumn{3}{|c|}{ Outer regime $(F=1)$} \\
\hline & Root & $\begin{array}{l}\text { Modulus } \\
\text { (half-life) }\end{array}$ & Period & Root & $\begin{array}{l}\text { Modulus } \\
\text { (half-life) }\end{array}$ & Period \\
\hline & $0.75 \pm 0.53 i$ & $0.91(8.6)$ & 10.3 & $0.03 \pm 0.94 i$ & $0.94(12.4)$ & 4.1 \\
\hline & $-0.70 \pm 0.70 i$ & $0.99(69.4)$ & 2.7 & & & \\
\hline \multirow{6}{*}{$\begin{array}{l}\text { Employment } \\
\text { (ESTAR) }\end{array}$} & \multicolumn{6}{|l|}{ Mid- regime $(F=0)$} \\
\hline & Root & Modulus & Period & & & \\
\hline & $-1.98 \pm 2.78 i$ & 3.41 & 2.9 & & & \\
\hline & \multicolumn{3}{|l|}{ Regime $F=0.7$} & \multicolumn{3}{|l|}{ Regime $F=0.95$} \\
\hline & Root & Modulus & Period & Root & Modulus & Period \\
\hline & $-0.72 \pm 1.792 i$ & 1.93 & 3.2 & $-0.22 \pm 0.88 i$ & $0.90(7.7)$ & 3.5 \\
\hline
\end{tabular}


Table 5.1

Nonlinear Granger noncausality tests.

The numbers denote the lag orders of the polynomial in the causing variable $(q=5, . .,(1) 0)$.

Asterisks indicate $p$-values: $*, p \leq 0.05 ; * *, p \leq 0.01 ; * * *, p \leq 0.001 ; * * * *, p \leq 0.0001$.

\begin{tabular}{|c|c|c|c|c|c|c|c|c|c|}
\hline \multirow[t]{2}{*}{ Caused variable } & \multicolumn{9}{|c|}{ Causing variable } \\
\hline & $\begin{array}{l}\text { Ind. } \\
\text { prod }\end{array}$ & GDP & Imp. & Exp. & Prod. & $\begin{array}{l}\text { Real } \\
\text { wages }\end{array}$ & Inv. & Cons. & Empl. \\
\hline $\begin{array}{l}\text { Industrial } \\
\text { production }\end{array}$ & & $\begin{array}{l}5 \\
6 \\
7 \\
8 * * \\
9 \\
0\end{array}$ & $\begin{array}{l}5 \\
6 \\
7 \\
8 \\
9 \\
0\end{array}$ & $\begin{array}{l}5 \\
6 \\
7 \\
8 \\
9 \\
0\end{array}$ & $\begin{array}{l}5 * \\
6 * * \\
7 * * * * \\
8 * * * * \\
9 * * * * \\
0 * * * *\end{array}$ & $\begin{array}{l}5 \\
6 \\
7 \\
8 \\
9 \\
0\end{array}$ & $\begin{array}{l}5^{*} \\
6 \\
7 * \\
8^{*} \\
9 \\
0^{*}\end{array}$ & $\begin{array}{l}5 \\
6 \\
7 \\
8 \\
9 \\
0\end{array}$ & $\begin{array}{l}* * \\
6 * \\
7 \\
8 * \\
9 \\
0 * * *\end{array}$ \\
\hline GDP & $\begin{array}{l}5 \\
6 \\
7 \\
8 \\
9 * * \\
0 * *\end{array}$ & & $\begin{array}{l}5 * \\
6 * \\
7 \\
8 \\
9 \\
0 *\end{array}$ & $\begin{array}{l}5 * \\
6 * \\
7 \\
8 \\
9 * \\
0\end{array}$ & $\begin{array}{l}5 * \\
6 \\
7 \\
8 * * \\
9 * * * \\
0 * * *\end{array}$ & $\begin{array}{l}5 * \\
6 * * \\
7 * \\
8 * \\
9 \\
0 * *\end{array}$ & $\begin{array}{l}5 \\
6 \\
7 \\
8 \\
9 \\
0\end{array}$ & $\begin{array}{l}5 \\
6 \\
7 \\
8 \\
9 \\
0\end{array}$ & $\begin{array}{l}5 \\
6 \\
7 * \\
8 * * \\
9 * * \\
0 * *\end{array}$ \\
\hline Imports & $\begin{array}{l}5 \\
6 \\
7 \\
8 \\
9 * * \\
0 * * *\end{array}$ & $\begin{array}{l}5 \\
6 \\
7 \\
8 \\
9 \\
0\end{array}$ & & $\begin{array}{l}5 * * * \\
6 * * * \\
7 * * * \\
8 * * \\
9 * * * * \\
0 * * * *\end{array}$ & $\begin{array}{l}5 \\
6 \\
7 \\
8 \\
9 * * \\
0 * *\end{array}$ & $\begin{array}{l}5 * \\
6 \\
7 * \\
8 * \\
9 * * \\
0 *\end{array}$ & $\begin{array}{l}5 \\
6 \\
7 * \\
8 * \\
9 * * \\
0 *\end{array}$ & $\begin{array}{l}5 * \\
6 * \\
7 * \\
8 * \\
9 * \\
0\end{array}$ & $\begin{array}{l}5 \\
6 * * \\
7 * \\
8 * \\
9 * * * \\
0 * *\end{array}$ \\
\hline Exports & $\begin{array}{l}5 \\
6 \\
7 \\
8 * \\
9 * \\
0 * * *\end{array}$ & $\begin{array}{l}5 * \\
6 * \\
7 \\
8 \\
9 * \\
0\end{array}$ & $\begin{array}{l}5 * \\
6 * \\
7 * \\
8 \\
9 \\
0\end{array}$ & & $\begin{array}{l}5 \\
6 \\
7 \\
8 * \\
9 * * \\
0 *\end{array}$ & $\begin{array}{l}5 \\
6 \\
7 \\
8 \\
9 \\
0 \\
0\end{array}$ & $\begin{array}{l}5 \\
6 \\
7 \\
8 \\
9 * \\
0 * *\end{array}$ & $\begin{array}{l}5 * * \\
6 * * * \\
7 * * * \\
8 * * \\
9 * * \\
0\end{array}$ & $\begin{array}{l}5 \\
6 * * \\
7 * * \\
8 * * \\
9 * * * \\
0 * * *\end{array}$ \\
\hline Productivity & $\begin{array}{l}* \\
6 * \\
7 * * * \\
8 * * \\
9 * * * \\
0 * * * *\end{array}$ & $\begin{array}{l}5 * * * \\
6 * * \\
7 * \\
8 * \\
9 * \\
0 * *\end{array}$ & $\begin{array}{l}5 * * \\
6 * * \\
7 * \\
8 * \\
9 * * \\
0 * * \\
\end{array}$ & $\begin{array}{l}5 * \\
6 * * \\
7 * \\
8 * * * \\
9 * * * \\
0 * *\end{array}$ & & $\begin{array}{l}5 * * \\
6 * \\
7 * \\
8 \\
9 * \\
0 * *\end{array}$ & $\begin{array}{l}5 \\
6 * \\
7 \\
8 * * \\
9 * * \\
0 * *\end{array}$ & $\begin{array}{l}5 * * * \\
6 * * * \\
7 * * \\
8 * * \\
9 * * * * \\
0 * *\end{array}$ & $\begin{array}{l}5 * * * \\
6 * * * \\
7 * * * \\
8 * * \\
9 * \\
0 * * * *\end{array}$ \\
\hline Real wages & $\begin{array}{l}5 \\
6 \\
7 \\
8 \\
9 \\
0\end{array}$ & $\begin{array}{l}5 * \\
6 * \\
7 * \\
8 * \\
9 * \\
0 *\end{array}$ & $\begin{array}{l}\text { 5**** } \\
6 * * * * \\
7 * * * * \\
8 * * * \\
9 * * * \\
0 * * *\end{array}$ & $\begin{array}{l}5 * * * * \\
6 * * * * \\
7 * * * * \\
8 * * * * \\
9 * * * * \\
0 * * *\end{array}$ & $\begin{array}{l}5 \\
6 \\
7 \\
8 \\
9 * * * \\
0 *\end{array}$ & & $\begin{array}{l}5 \\
6 \\
7 \\
8 \\
9 \\
0\end{array}$ & $\begin{array}{l}5 * * * * \\
6 * * * * \\
7 * * * * \\
8 * * * \\
9 * * * \\
0 * *\end{array}$ & $\begin{array}{l}5 \\
6 * * \\
7 * * \\
8 * * \\
9 \\
0\end{array}$ \\
\hline Investment $^{\dagger}$ & $\begin{array}{l}\text { 5** } \\
6 * * \\
7 * * \\
8 * * \\
9 * * * \\
0 * * \\
\end{array}$ & $\begin{array}{l}5 \\
6 \\
7 \\
8 \\
9 \\
0\end{array}$ & $\begin{array}{l}5 \\
6 \\
7 * \\
8 \\
9 \\
0\end{array}$ & $\begin{array}{l}5 \\
6 \\
7 \\
8 \\
9 \\
0\end{array}$ & $\begin{array}{l}5 * * \\
6 * * \\
7 * \\
8 * \\
9 * \\
0 * * *\end{array}$ & $\begin{array}{l}5 \\
6 \\
7 \\
8 \\
9 \\
0 \\
0\end{array}$ & & $\begin{array}{l}5 \\
6 \\
7 \\
8 \\
9 \\
0\end{array}$ & $\begin{array}{l}5 \\
6 \\
7 \\
8 \\
9 * \\
0 * * *\end{array}$ \\
\hline Consumption & $\begin{array}{l}5 \\
6 \\
7 * \\
8 * \\
9 * * * \\
0 * * * *\end{array}$ & $\begin{array}{l}5 * * \\
6 * * * \\
7 * * \\
8 * * \\
9 * \\
0 * *\end{array}$ & $\begin{array}{l}\text { 5** } \\
6 * * \\
7 * * \\
8 * * \\
9 * \\
0\end{array}$ & $\begin{array}{l}5 * * \\
6 * * * * \\
7 * * * * \\
8 * * * \\
9 * * \\
0 *\end{array}$ & $\begin{array}{l}5 \\
6 \\
7 * \\
8 * \\
9 \\
0\end{array}$ & $\begin{array}{l}5 \\
6 \\
7 * \\
8 * * \\
9 * * \\
0 * *\end{array}$ & $\begin{array}{l}5 \\
6 \\
7 * \\
8 \\
9 \\
0\end{array}$ & & $\begin{array}{l}5 \\
6 \\
7 \\
8 \\
9 \\
0\end{array}$ \\
\hline Employment & $\begin{array}{l}5 \\
6 * \\
7 * * \\
8 * * * \\
9 * * * * \\
0 * * * *\end{array}$ & $\begin{array}{l}5 * * * \\
6 * * * \\
7 * * \\
8 * \\
9 \\
0 \\
\end{array}$ & $\begin{array}{l}5 * * * \\
6 * * * \\
7 * * \\
8 * * \\
9 * \\
0 * *\end{array}$ & $\begin{array}{l}5 \\
6 * * \\
7 * * \\
8 * * * \\
9 * * \\
0 *\end{array}$ & $\begin{array}{l}5 * \\
6 * * * \\
7 * \\
8 * * \\
9 * * \\
0 \\
\end{array}$ & $\begin{array}{l}5 \\
6 \\
7 \\
8 \\
9 \\
0\end{array}$ & $\begin{array}{l}5 \\
6 \\
7 \\
8 \\
9 \\
0 \text { ** }\end{array}$ & $\begin{array}{l}5 \\
6 \\
7 \\
8 \\
9 \\
0 \\
0\end{array}$ & \\
\hline
\end{tabular}

'Computed from observations for 1876-1988 
Table 5.2

Linear Granger noncausality tests.

The numbers denote the lag orders of the polynomial in the causing variable $(q=5, . .,(1) 0)$.

Asterisks indicate $p$-values: ${ }^{*}, p \leq 0.05$; $^{*}, p \leq 0.01$; ***, $p \leq 0.001 ; * * * *, p \leq 0.0001$.

\begin{tabular}{|c|c|c|c|c|c|c|c|c|c|}
\hline \multirow[t]{2}{*}{ Caused variable } & \multicolumn{9}{|c|}{ Causing variable } \\
\hline & $\begin{array}{l}\text { Ind. } \\
\text { prod }\end{array}$ & GDP & Imp. & Exp. & Prod. & $\begin{array}{l}\text { Real } \\
\text { wages }\end{array}$ & Inv. & Cons. & Empl. \\
\hline $\begin{array}{l}\text { Industrial } \\
\text { production }\end{array}$ & & $\begin{array}{l}5 \\
6 \\
7 \\
8 \\
9 \\
0\end{array}$ & $\begin{array}{l}5 \\
6 \\
7 \\
8 \\
9 \\
0\end{array}$ & $\begin{array}{l}5 \\
6 \\
7 \\
8 \\
9 \\
0\end{array}$ & $\begin{array}{l}5 \\
6 \\
7 \\
8 \\
9 \\
0 *\end{array}$ & $\begin{array}{l}5 \\
6 \\
7 \\
8 \\
9 \\
0\end{array}$ & $\begin{array}{l}5 \\
6 \\
7 \\
8 \\
9 \\
0\end{array}$ & $\begin{array}{l}5 \\
6 \\
7 \\
8 \\
9 \\
0\end{array}$ & $\begin{array}{l}5 \\
6 \\
7 \\
8 \\
9 \\
0 *\end{array}$ \\
\hline GDP & $\begin{array}{l}5 \\
6 \\
7 \\
8 \\
9 \\
0\end{array}$ & & $\begin{array}{l}5 \\
6 \\
7 \\
8 \\
9 \\
0\end{array}$ & $\begin{array}{l}5 * * \\
6 * * \\
7 * * \\
8 * \\
9 * \\
0\end{array}$ & $\begin{array}{l}5 * \\
6 \\
7 \\
8 \\
9 \\
0\end{array}$ & $\begin{array}{l}5 * * \\
6 * * \\
7 * \\
8 * * \\
9 * \\
0 * *\end{array}$ & $\begin{array}{l}5 \\
6 \\
7 \\
8 \\
9 \\
0\end{array}$ & $\begin{array}{l}5 \\
6 \\
7 \\
8 \\
9 \\
0\end{array}$ & $\begin{array}{l}5 \\
6 \\
7 \\
8 \\
9 \\
0\end{array}$ \\
\hline Imports & $\begin{array}{l}5 \\
6 \\
7 \\
8 \\
9 \\
0\end{array}$ & $\begin{array}{l}5 \\
6 \\
7 \\
8 \\
9 \\
0\end{array}$ & & $\begin{array}{l}5 * * * \\
6 * * * \\
7 * * * \\
8 * \\
9 * \\
0 *\end{array}$ & $\begin{array}{l}5 \\
6 \\
7 \\
8 \\
9 \\
0\end{array}$ & $\begin{array}{l}5 * \\
6 * \\
7 * * \\
8 * * \\
9 * * \\
0 * *\end{array}$ & $\begin{array}{l}5 \\
6 \\
7 \\
8 \\
9 \\
0\end{array}$ & $\begin{array}{l}5 * \\
6 \\
7 \\
8 \\
9 \\
0\end{array}$ & $\begin{array}{l}5 \\
6 \\
7 \\
8 \\
9 \\
0\end{array}$ \\
\hline Exports & $\begin{array}{l}5 \\
6 \\
7 \\
8 \\
9 \\
0\end{array}$ & $\begin{array}{l}5 * \\
6 \\
7 \\
8 \\
9 \\
0\end{array}$ & $\begin{array}{l}5 \\
6 \\
7 \\
8 \\
9 \\
0\end{array}$ & & $\begin{array}{l}5 * \\
6 * * \\
7 * \\
8 * \\
9 * \\
0 *\end{array}$ & $\begin{array}{l}5 * * * \\
6 * * * \\
7 * * * * \\
8 * * * \\
9 * * * \\
0 * *\end{array}$ & $\begin{array}{l}5 \\
6 \\
7 \\
8 \\
9 \\
0\end{array}$ & $\begin{array}{l}5 \\
6 \\
7 \\
8 \\
9 * \\
0 *\end{array}$ & $\begin{array}{l}5 \\
6 * * \\
7 * * \\
8 * * \\
9 * \\
0 *\end{array}$ \\
\hline Productivity & $\begin{array}{l}5 * \\
6 * \\
7 * \\
8 * * \\
9 * \\
0 *\end{array}$ & $\begin{array}{l}5 \\
6 \\
7 \\
8 \\
9 \\
0\end{array}$ & $\begin{array}{l}5 \\
6 \\
7 \\
8 \\
9 \\
0\end{array}$ & $\begin{array}{l}5 \\
6 \\
7 \\
8 \\
9 \\
0\end{array}$ & & $\begin{array}{l}5 * * * \\
6 * * * \\
7 * * * \\
8 * * \\
8 * * \\
9 * * \\
0 *\end{array}$ & $\begin{array}{l}5 \\
6 \\
7 \\
8 \\
9 \\
0\end{array}$ & $\begin{array}{l}5 * \\
6 * \\
7 \\
8 \\
9 \\
0\end{array}$ & $\begin{array}{l}5 * \\
6 * \\
7 * \\
8 * \\
9 * \\
0 *\end{array}$ \\
\hline Real wages & $\begin{array}{l}5 \\
6 \\
7 \\
8 \\
9 \\
0\end{array}$ & $\begin{array}{l}5 * \\
6 * \\
7 * \\
8 * \\
9 \\
0\end{array}$ & $\begin{array}{l}5 \\
6 * * \\
7 * * * \\
8 * * * * \\
9 * * * * \\
0 * * *\end{array}$ & $\begin{array}{l}5 \\
6 \\
7 \\
8 \\
9 \\
0\end{array}$ & $\begin{array}{l}5 \\
6 \\
7 \\
8 \\
9 \\
0\end{array}$ & & $\begin{array}{l}5 \\
6 \\
7 \\
8 \\
9 \\
0\end{array}$ & $\begin{array}{l}5 * \\
6 \\
7 * \\
8 * * \\
9 * \\
0 *\end{array}$ & $\begin{array}{l}5 \\
6 \\
7 \\
8 \\
9 \\
0\end{array}$ \\
\hline Investment $^{\dagger}$ & $\begin{array}{l}5 * \\
6 * * * \\
7 * * * \\
8 * * * \\
9 * * * \\
0 * * *\end{array}$ & $\begin{array}{l}5 \\
6 \\
7 \\
8 \\
9 \\
0\end{array}$ & $\begin{array}{l}5 * \\
6 \\
7 \\
8 \\
9 \\
0\end{array}$ & $\begin{array}{l}5 * \\
6 * \\
7 * \\
8 * \\
9 * \\
0 *\end{array}$ & $\begin{array}{l}5 * \\
6 * \\
7 * \\
8 * \\
9 * \\
0 *\end{array}$ & $\begin{array}{l}5 \\
6 \\
7 \\
8 \\
9 \\
0\end{array}$ & & $\begin{array}{l}5 \\
6 * \\
7 \\
8 * * \\
9 * * \\
0 *\end{array}$ & $\begin{array}{l}5 \\
6 \\
7 \\
8 \\
9 \\
0\end{array}$ \\
\hline Consumption & $\begin{array}{l}5 \\
6 \\
7 \\
8 \\
9 \\
0\end{array}$ & $\begin{array}{l}5 \\
6 \\
7 \\
8 \\
9 \\
0\end{array}$ & $\begin{array}{l}5 * \\
6 \\
7 \\
8 \\
9 \\
0\end{array}$ & $\begin{array}{l}5 * * \\
6 * * * \\
7 * * * \\
8 * * * \\
9 * * * \\
0 * * *\end{array}$ & $\begin{array}{l}5 \\
6 \\
7 \\
8 \\
9 \\
0\end{array}$ & $\begin{array}{l}5 * \\
6^{*} \\
7 * \\
8 * \\
9 \\
0\end{array}$ & $\begin{array}{l}5 \\
6 \\
7 \\
8 \\
9 \\
0\end{array}$ & & $\begin{array}{l}5 \\
6 \\
7 * \\
8 \\
9 * \\
0 *\end{array}$ \\
\hline Employment & $\begin{array}{l}5 \\
6 \\
7 \\
8 \\
9 \\
0\end{array}$ & $\begin{array}{l}5 * * \\
6 * * \\
7 * \\
8 * \\
9 * \\
0\end{array}$ & $\begin{array}{l}5 \\
6 \\
7 \\
8 \\
9 \\
0\end{array}$ & $\begin{array}{l}5 \\
6 * \\
7 \\
8 * \\
9 * \\
0\end{array}$ & $\begin{array}{l}5 \\
6 \\
7 \\
8 \\
9 \\
0\end{array}$ & $\begin{array}{l}5 * * \\
6 * * \\
7 * * \\
8 * * \\
9 * \\
0 *\end{array}$ & $\begin{array}{l}5 \\
6 \\
7 \\
8 \\
9 \\
0\end{array}$ & $\begin{array}{l}5 * * \\
6 * \\
7 * \\
8 * \\
9 * \\
0 *\end{array}$ & \\
\hline
\end{tabular}

${ }^{\dagger}$ Computed from observations for 1876-1988 


\section{FIGURES}
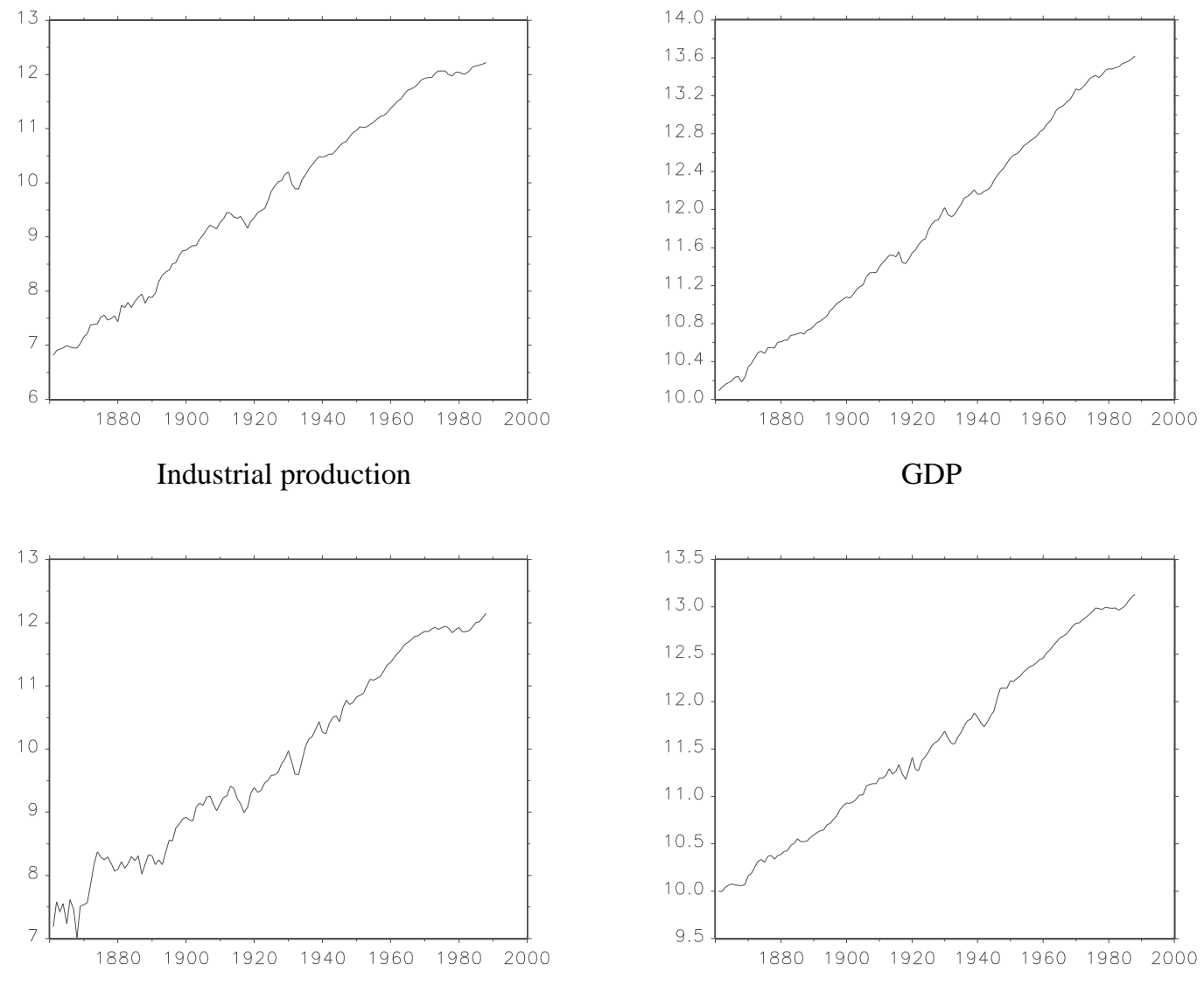

Investment

Consumption
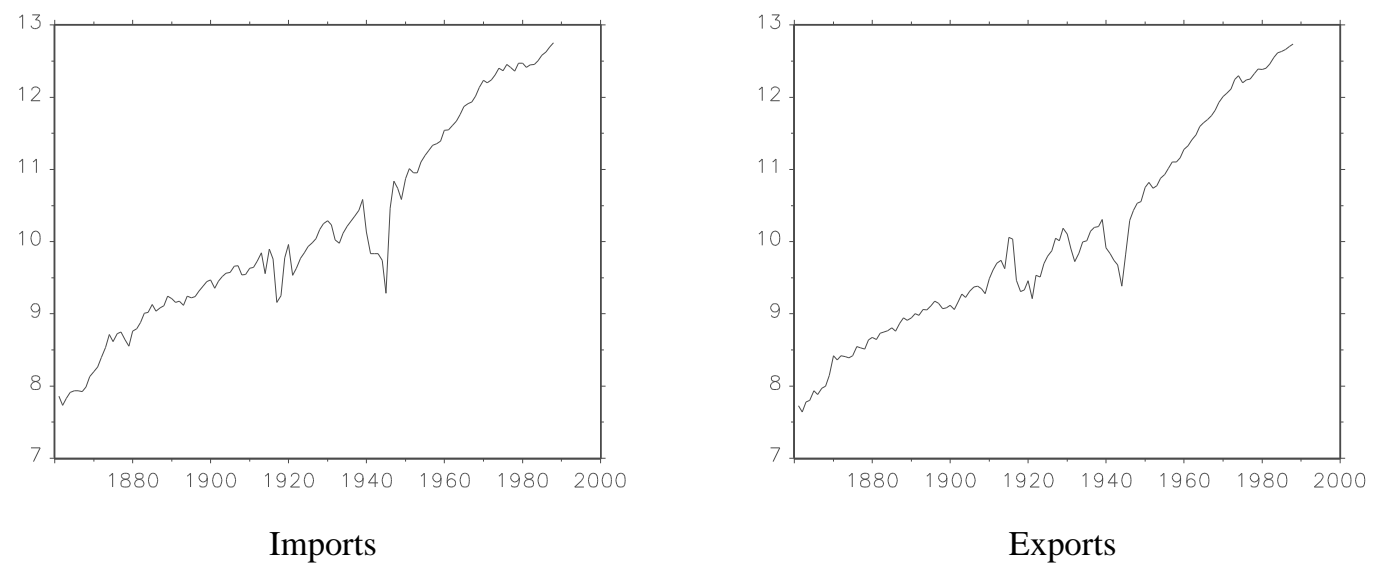

Figure 2.1 Logarithms of the series 
(Figure 2.1, continued)

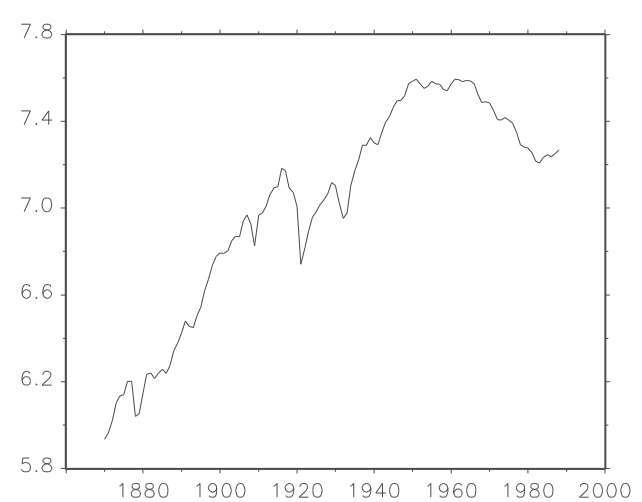

Employment

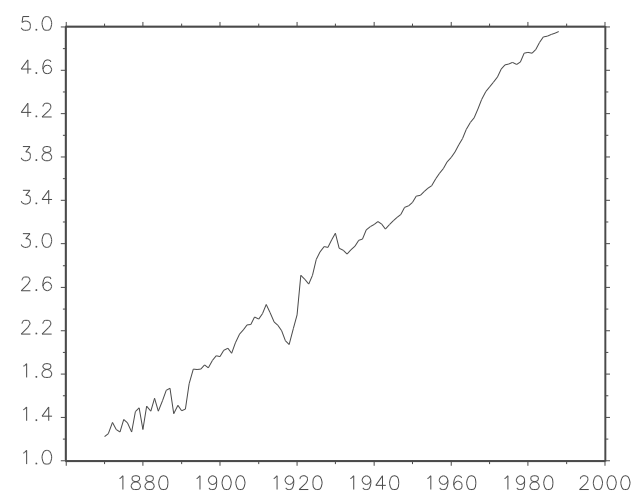

Productivity

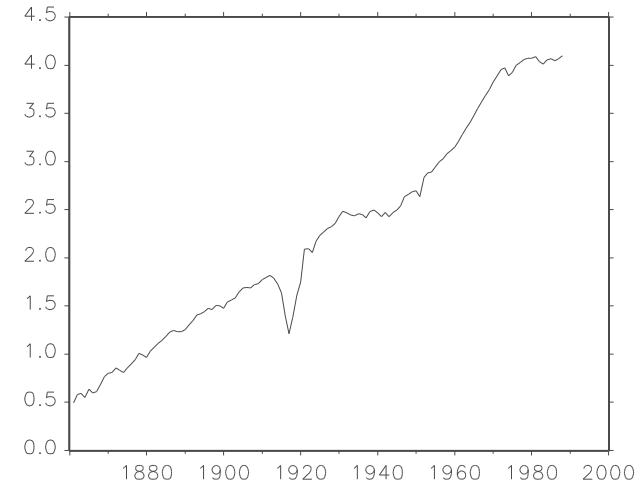

Real wages 


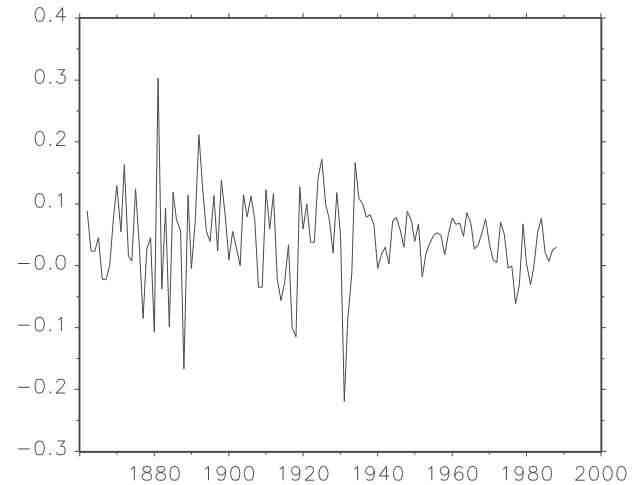

Industrial production

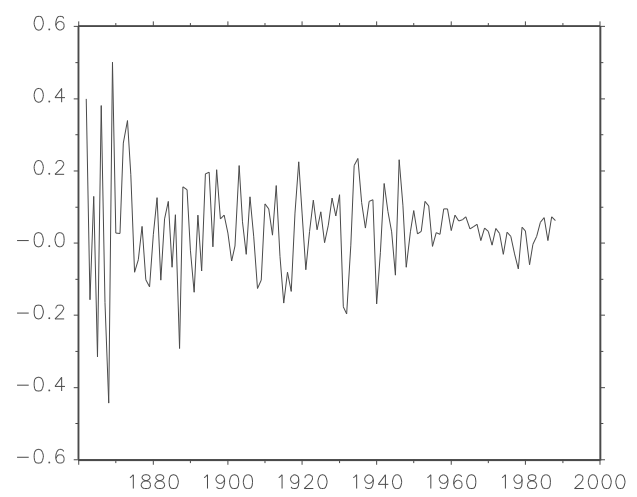

Investment

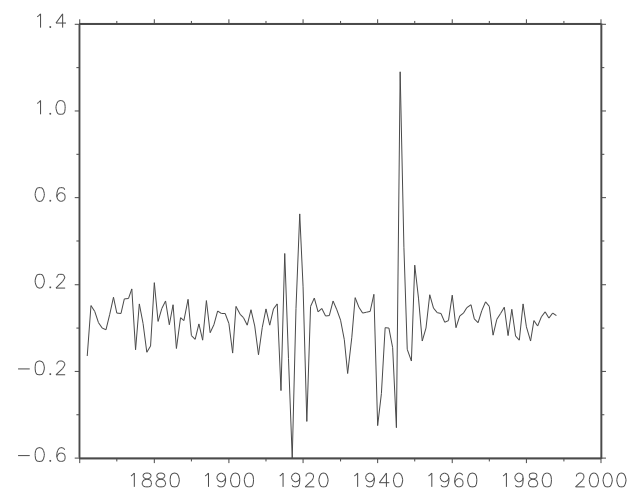

Imports
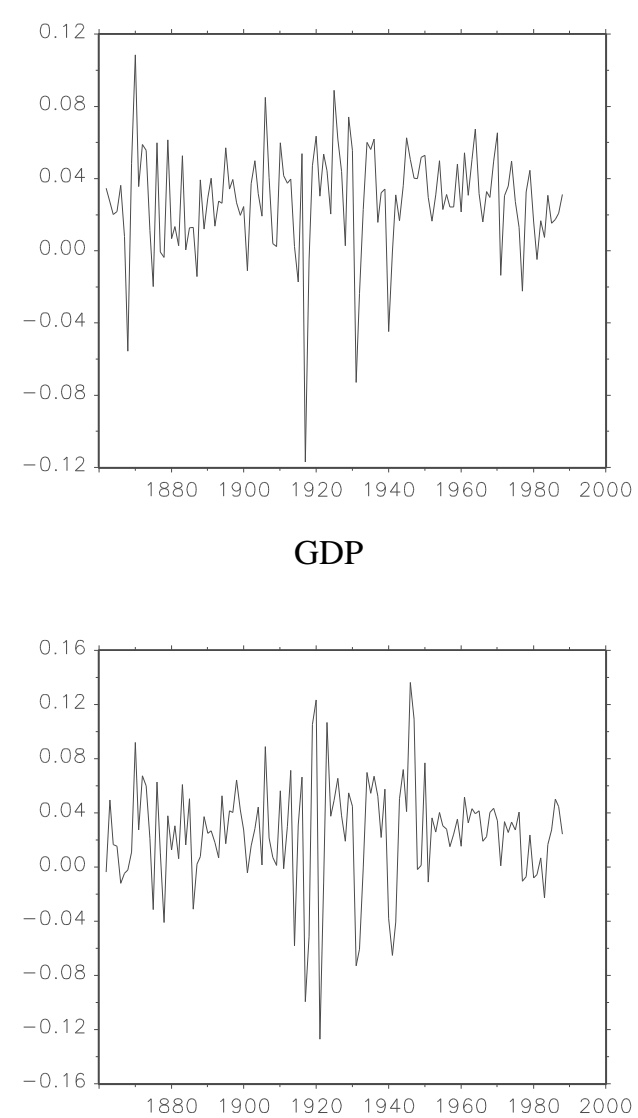

Consumption

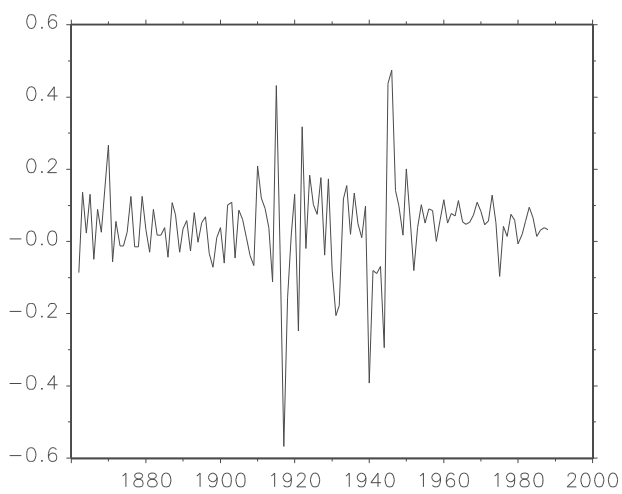

Exports

Figure 2.2 First differences of the logarithms of the series 
(Figure 2.2, continued)

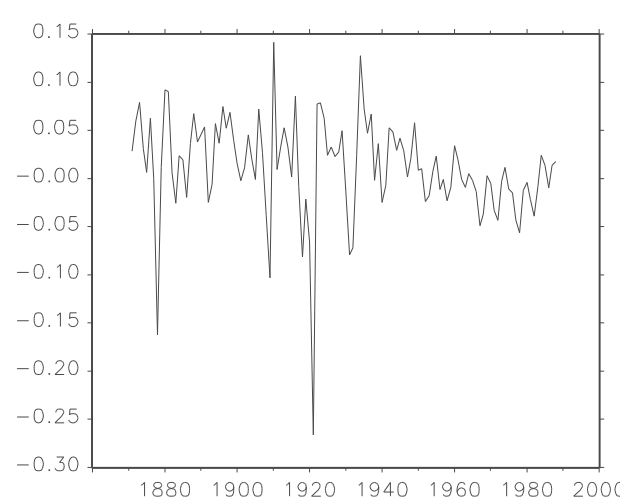

Employment

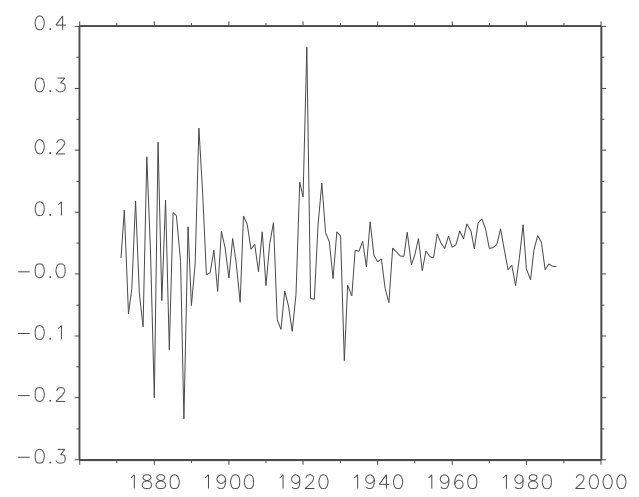

Productivity

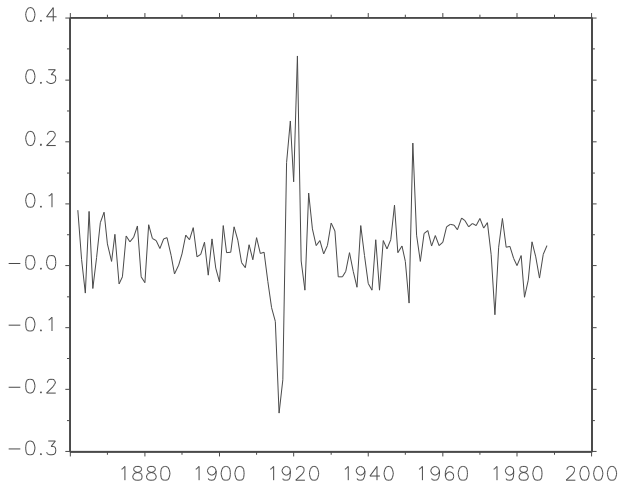

Real wages 


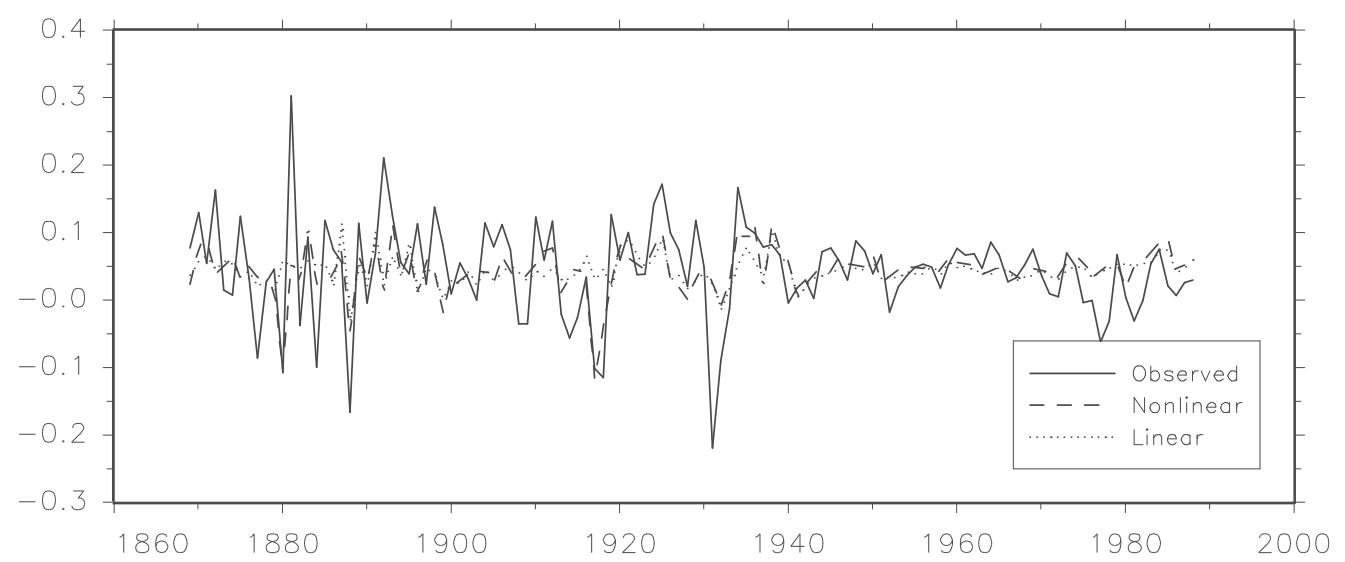

Fig. 4.1. Industrial production (first difference of logarithm). Observed values, predictions from STAR model, and predictions from AR model.

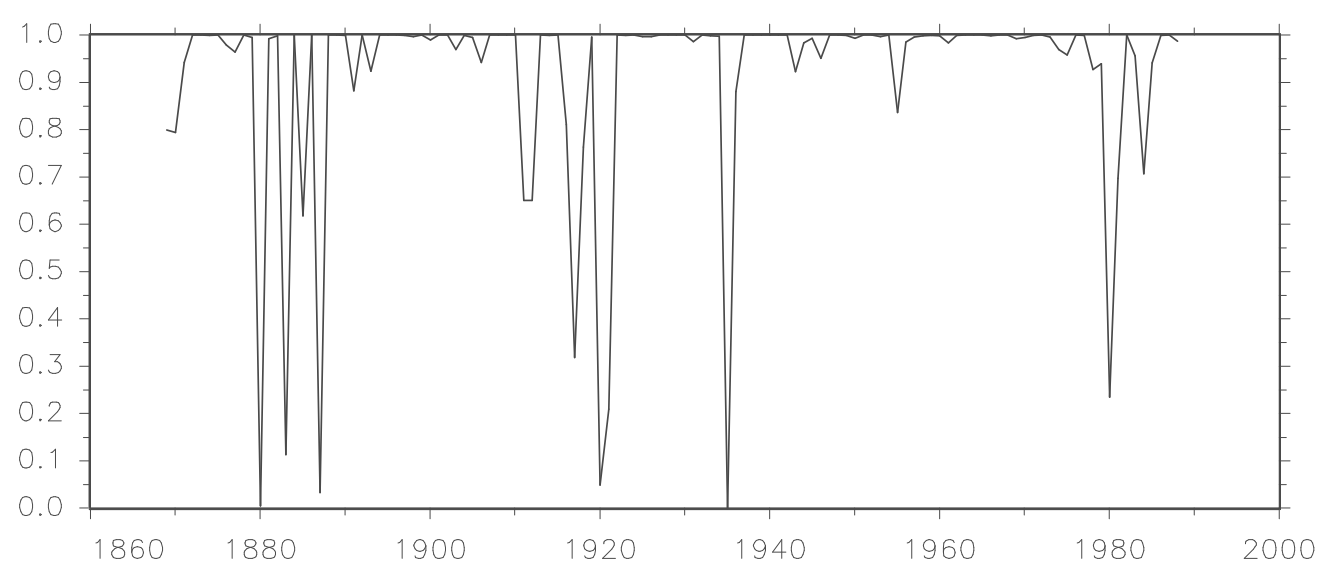

Fig. 4.2. Industrial production (first difference of logarithm). Estimated transition function over time.

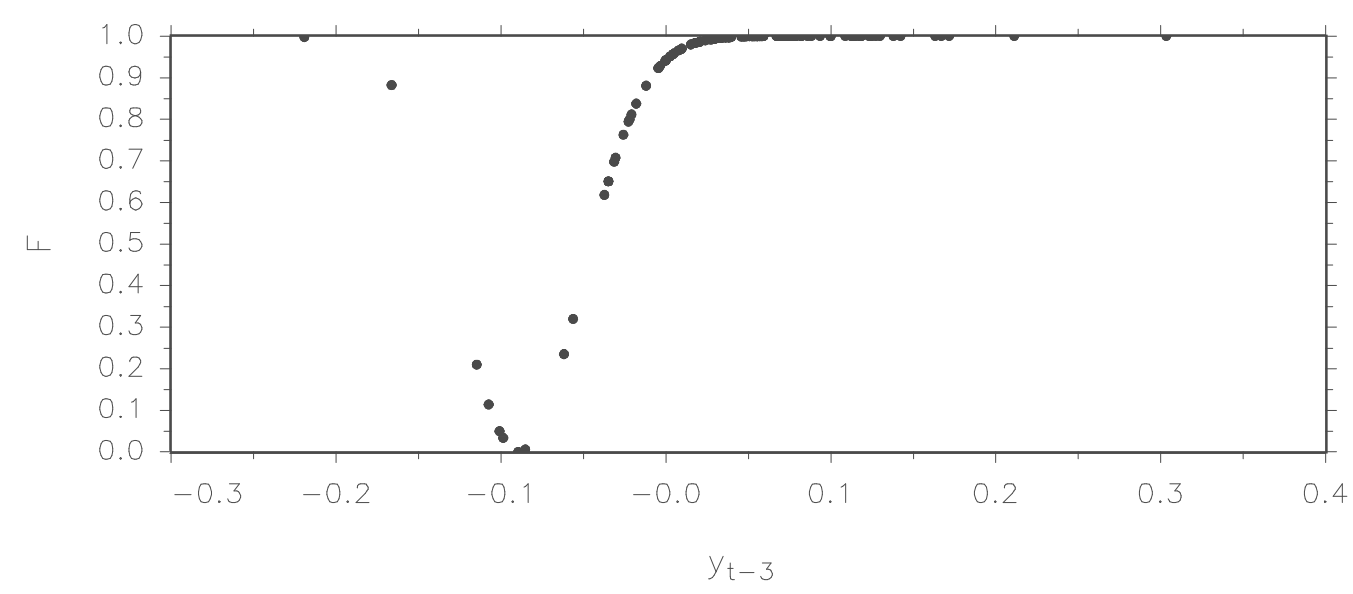

Fig. 4.3. Industrial production (first difference of logarithm). Estimated transition function vs the transition variable. 


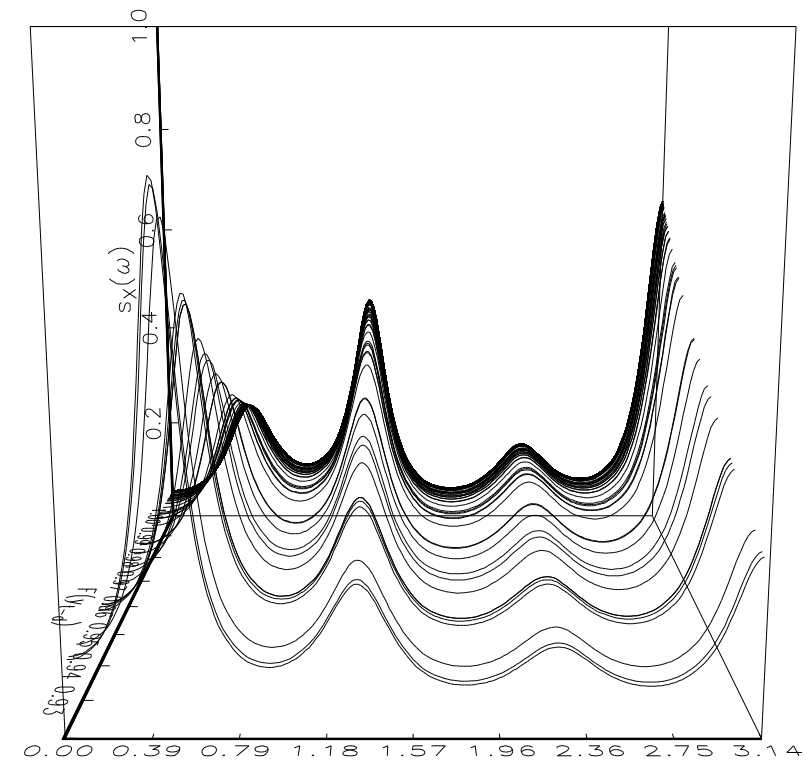

Fig. 4.4. Industrial production (first difference of logarithm). 'Sliced' spectra.

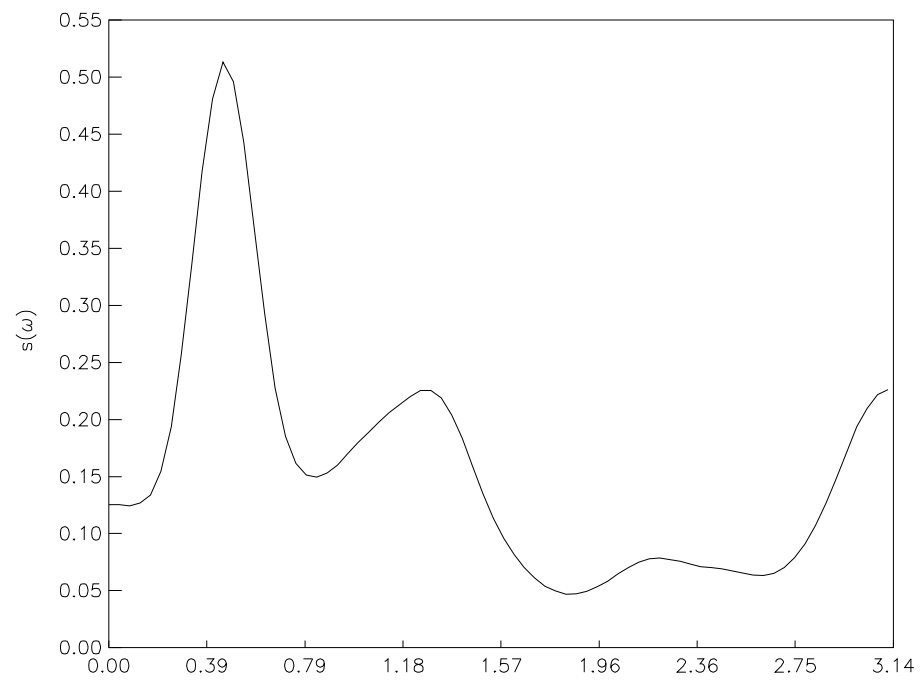

Fig. 4.5. Industrial production (first difference of logarithm). Model spectrum. 


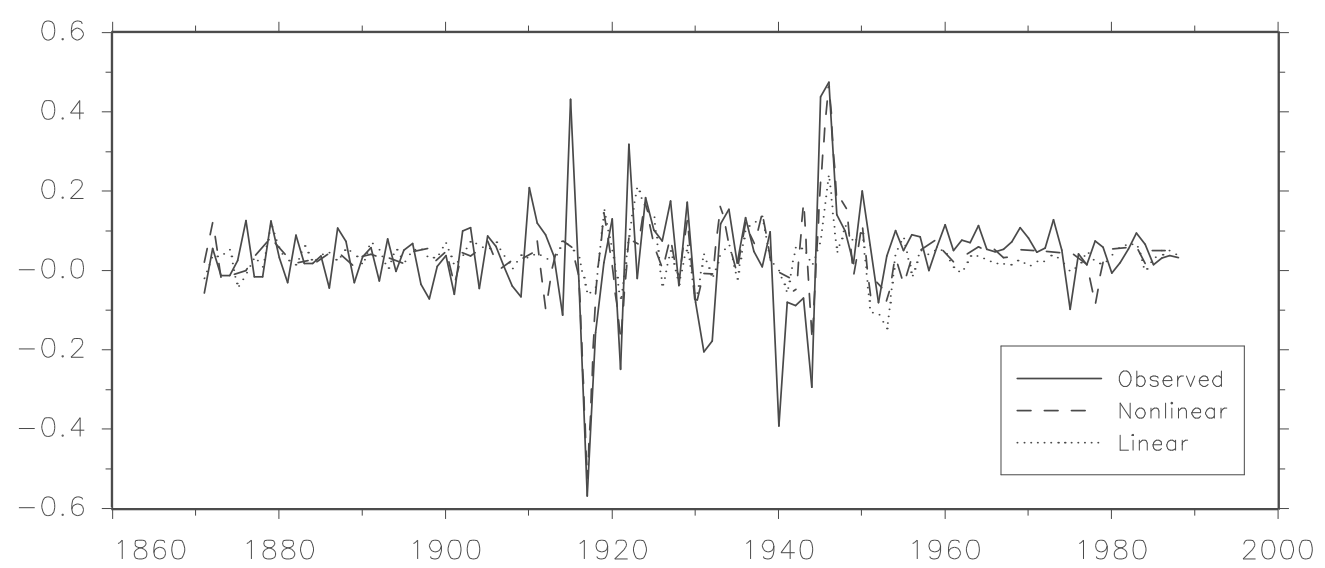

Fig. 4.6. Exports (first difference of logarithm). Observed values, predictions from STAR model, and predictions from AR model.

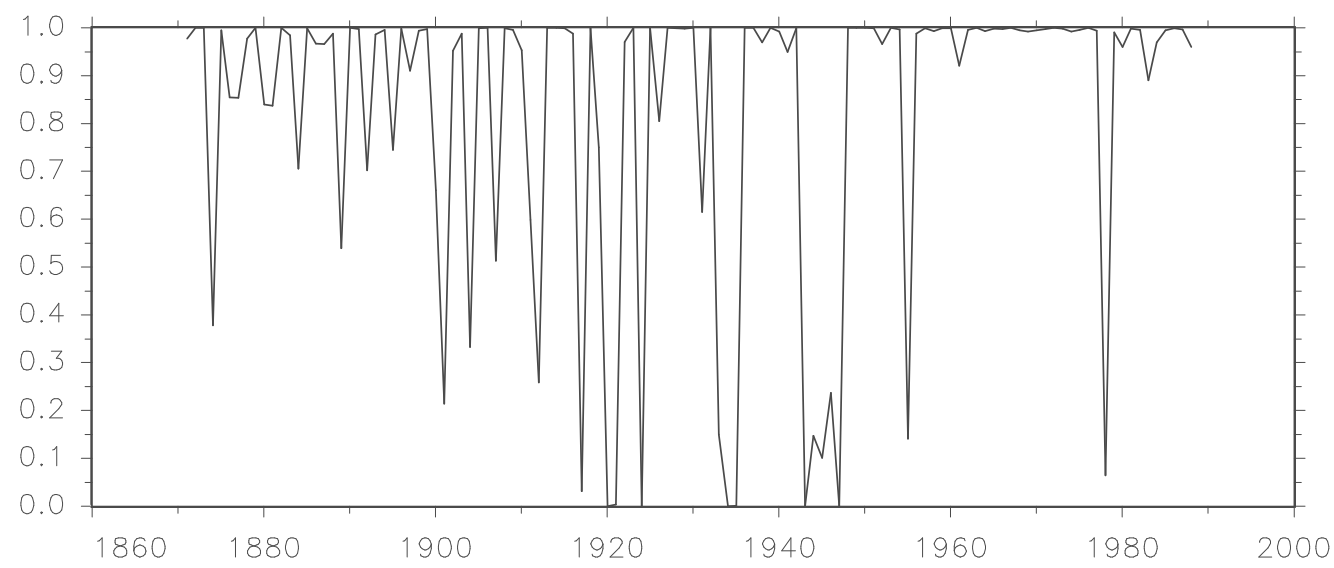

Fig. 4.7. Exports (first difference of logarithm). Estimated transition function over time.

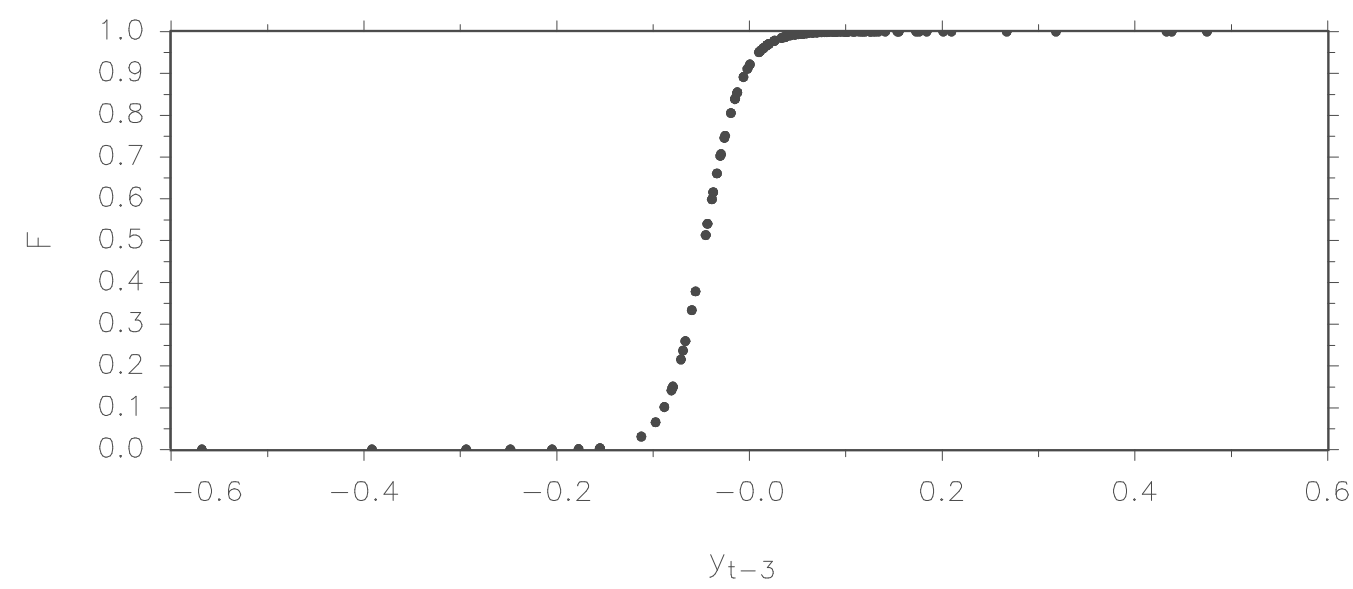

Fig. 4.8. Exports (first difference of logarithm). Estimated transition function vs the transition variable. 


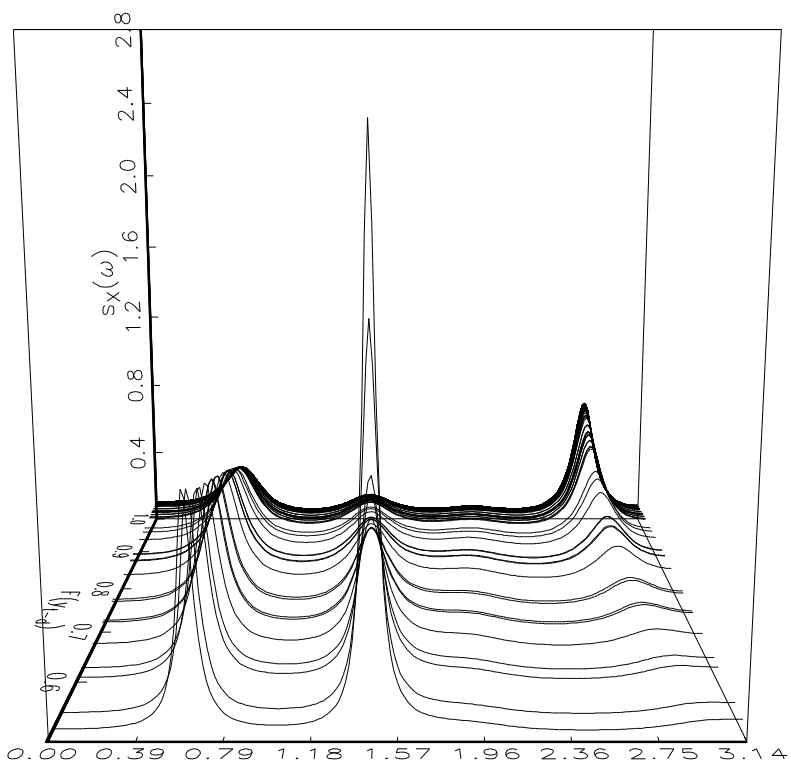

Fig. 4.9. Exports (first difference of logarithm). 'Sliced' spectra.

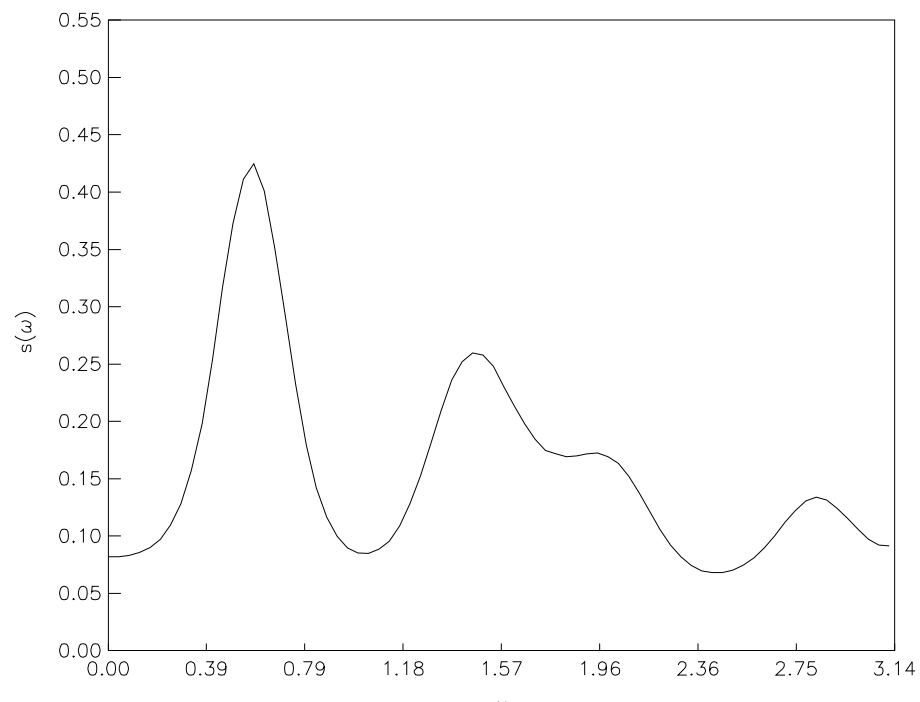

Fig. 4.10. Exports (first difference of logarithm). Model spectrum. 


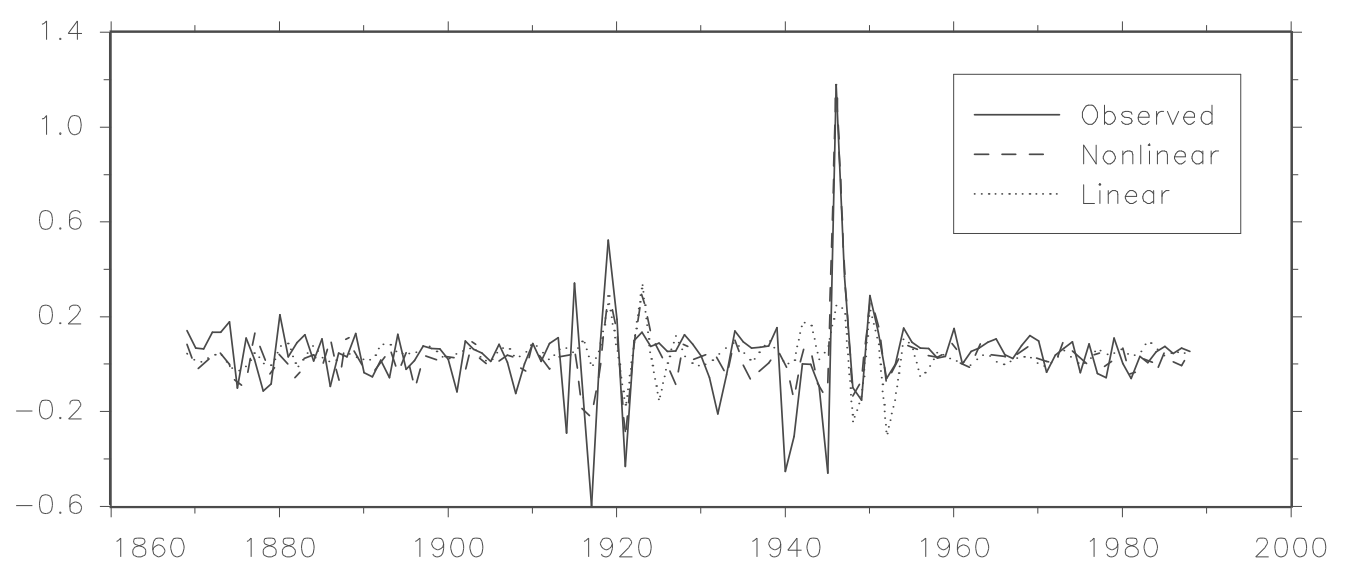

Fig. 4.11. Imports (first difference of logarithm). Observed values, predictions from STAR model, and predictions from AR model.

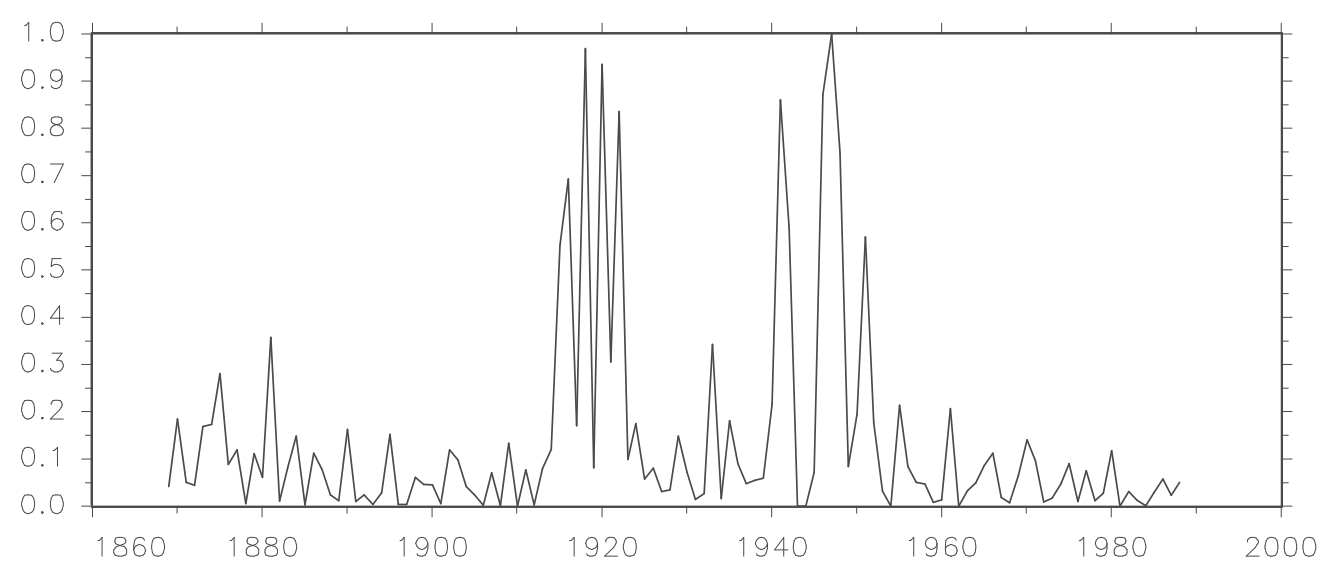

Fig. 4.12. Imports (first difference of logarithm). Estimated transition function over time.

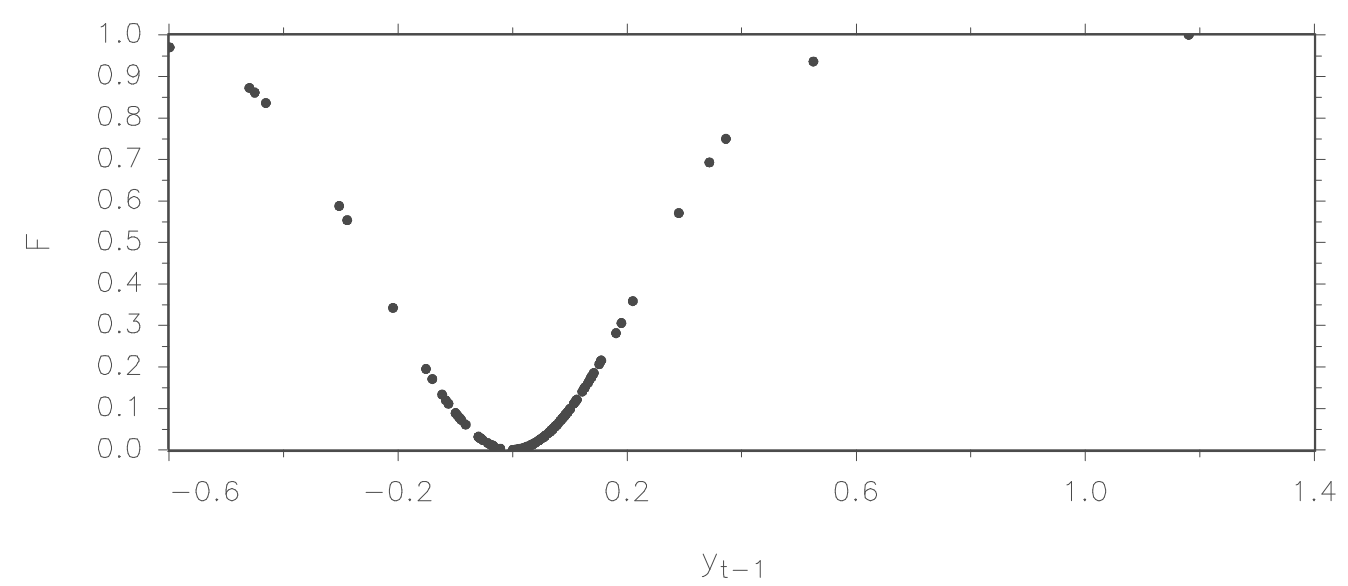

Fig. 4.13. Imports (first difference of logarithm). Estimated transition function vs the transition variable. 


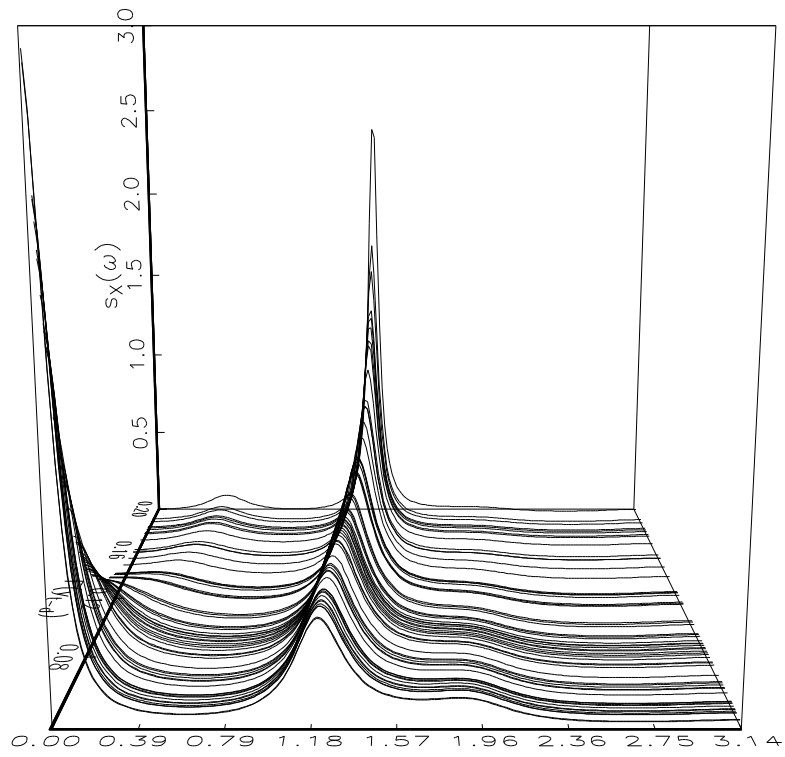

Fig. 4.14. Imports (first difference of logarithm). 'Sliced' spectra. 


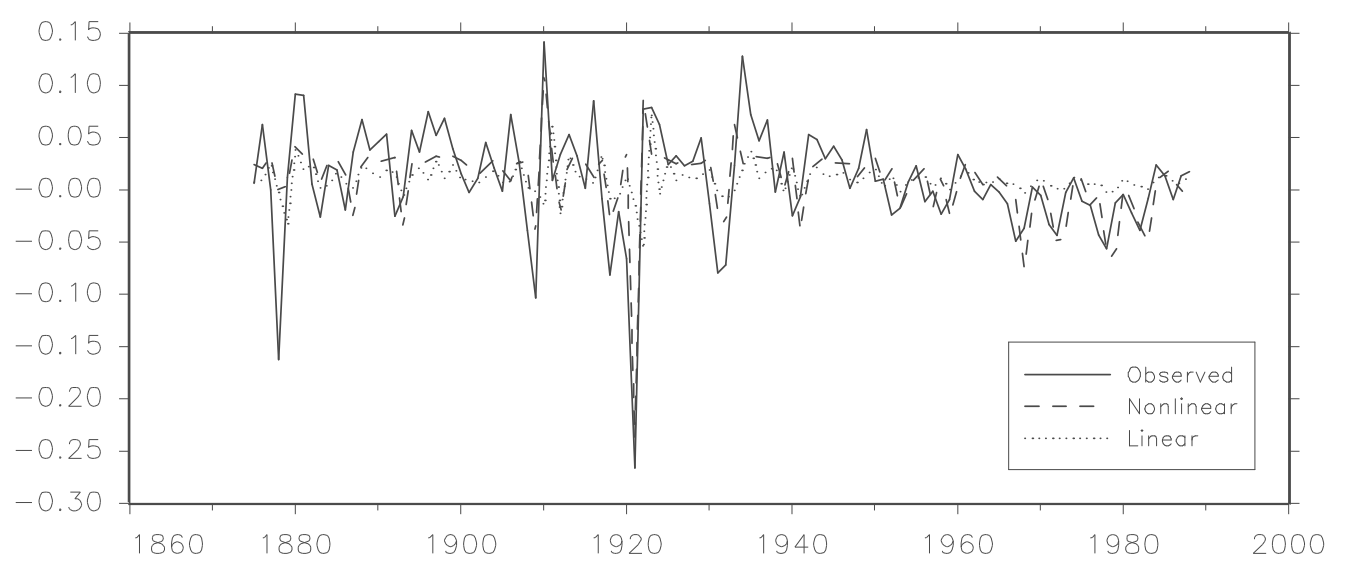

Fig. 4.15. Employment (first difference of logarithm). Observed values, predictions from STAR model, and predictions from AR model.

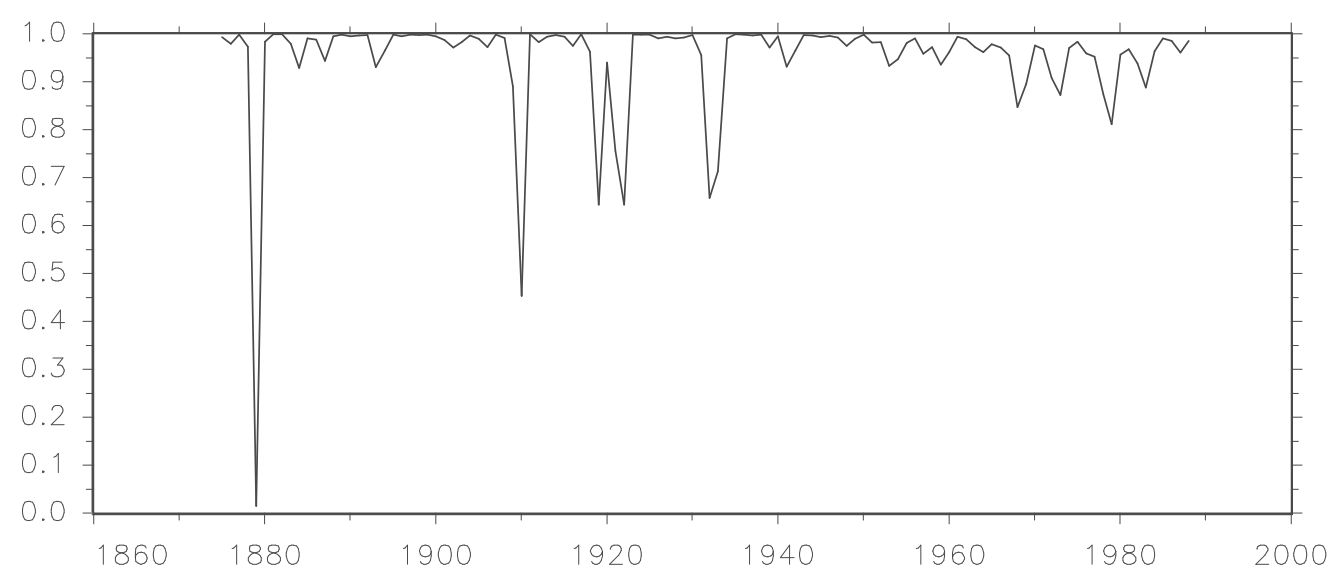

Fig. 4.16. Employment (first difference of logarithm). Estimated transition function over time.

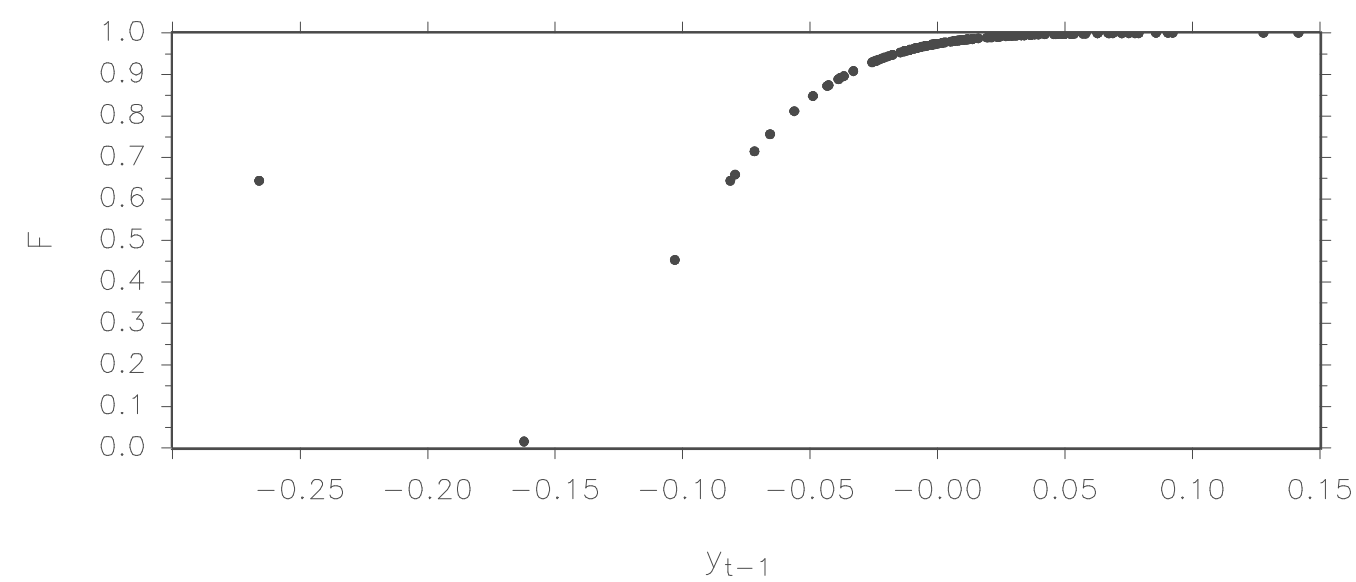

Fig. 4.17. Employment (first difference of logarithm). Estimated transition function vs the transition variable. 


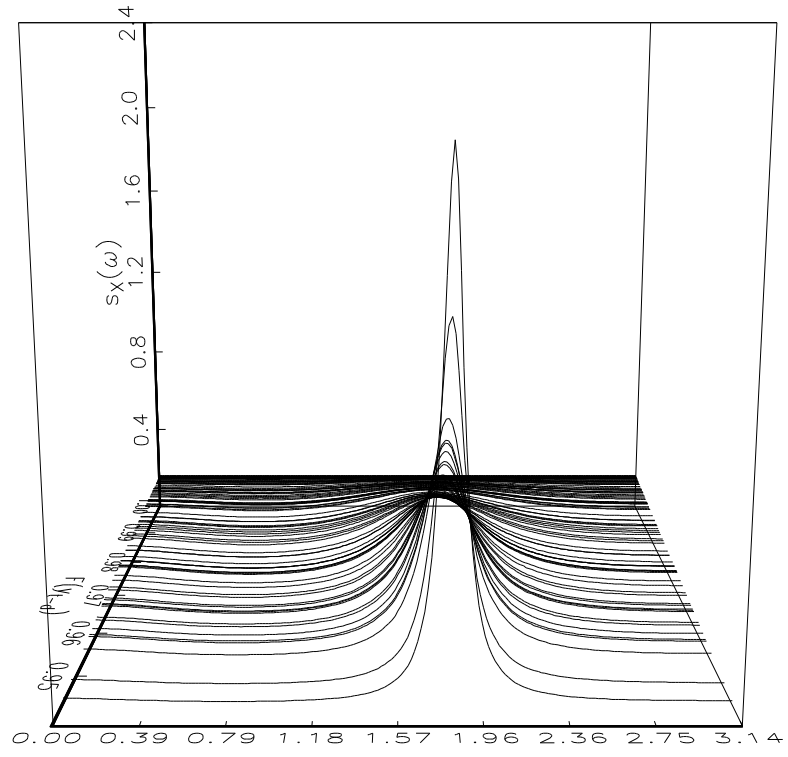

Fig. 4.18. Employment (first difference of logarithm). 'Sliced' spectra.

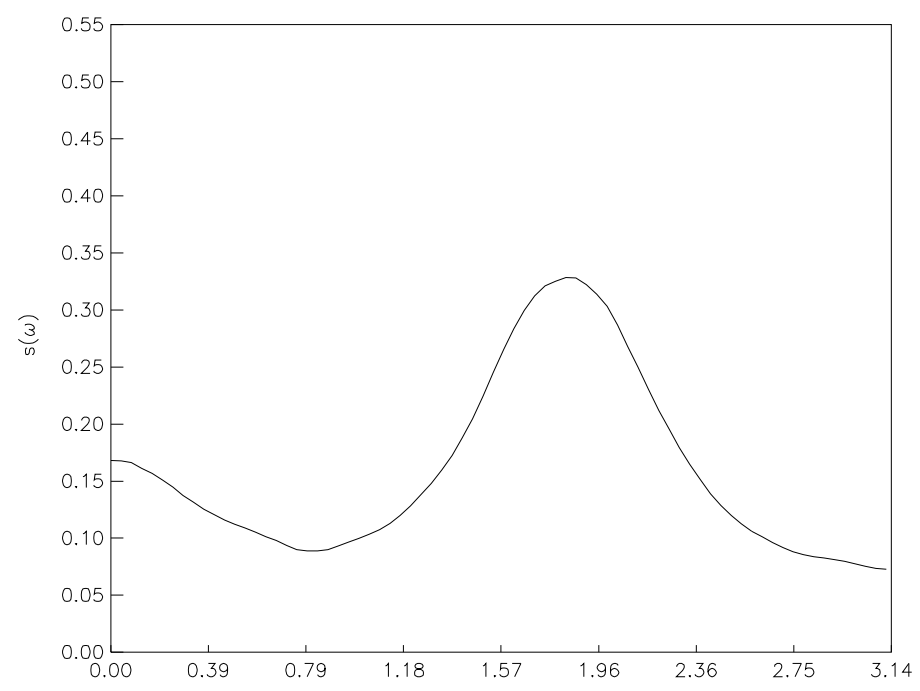

Fig. 4.19. Employment (first difference of logarithm). Model spectrum. 


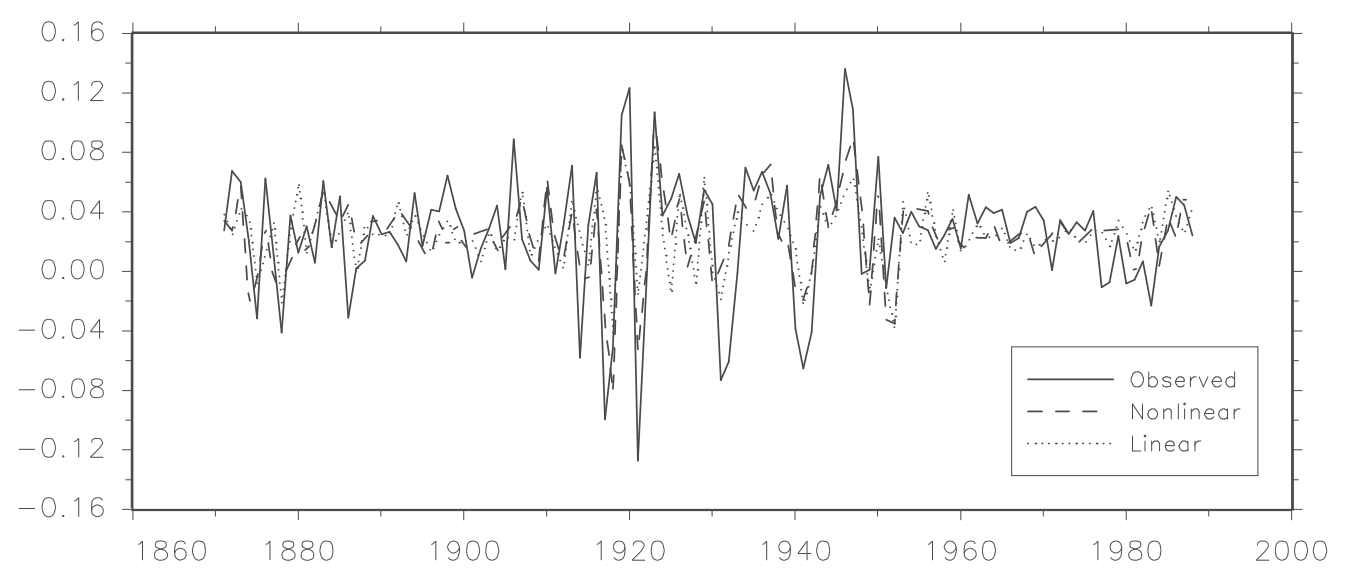

Fig. 4.20. Consumption (first difference of logarithm). Observed values, predictions from STAR model, and predictions from AR model.

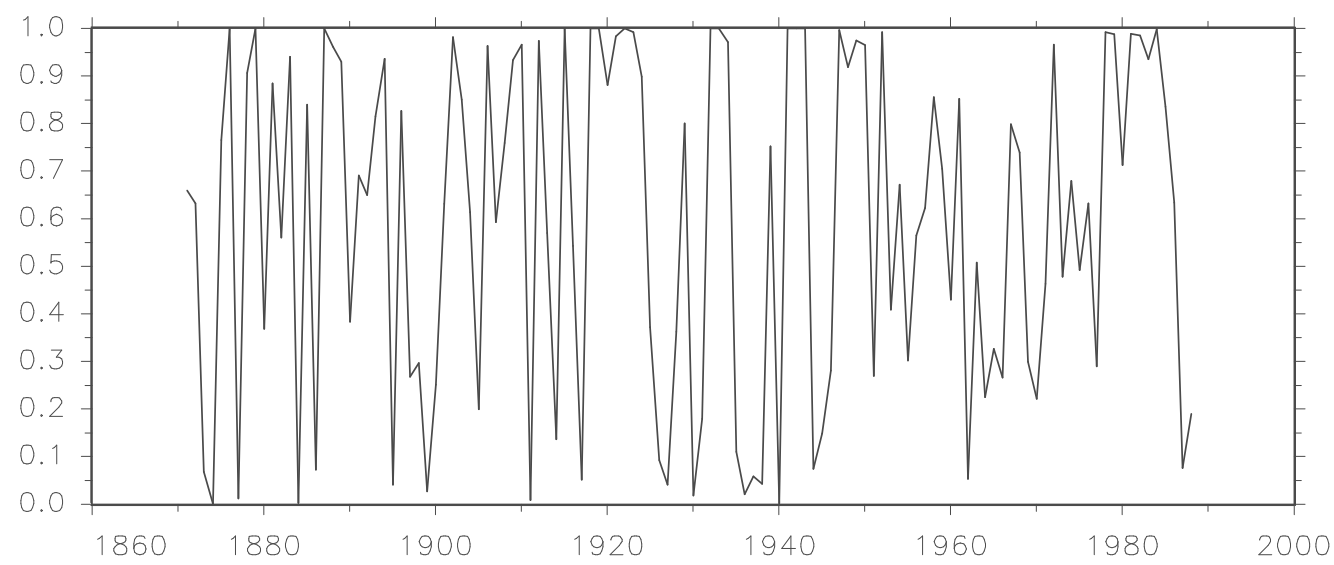

Fig. 4.21. Consumption (first difference of logarithm). Estimated transition function over time.

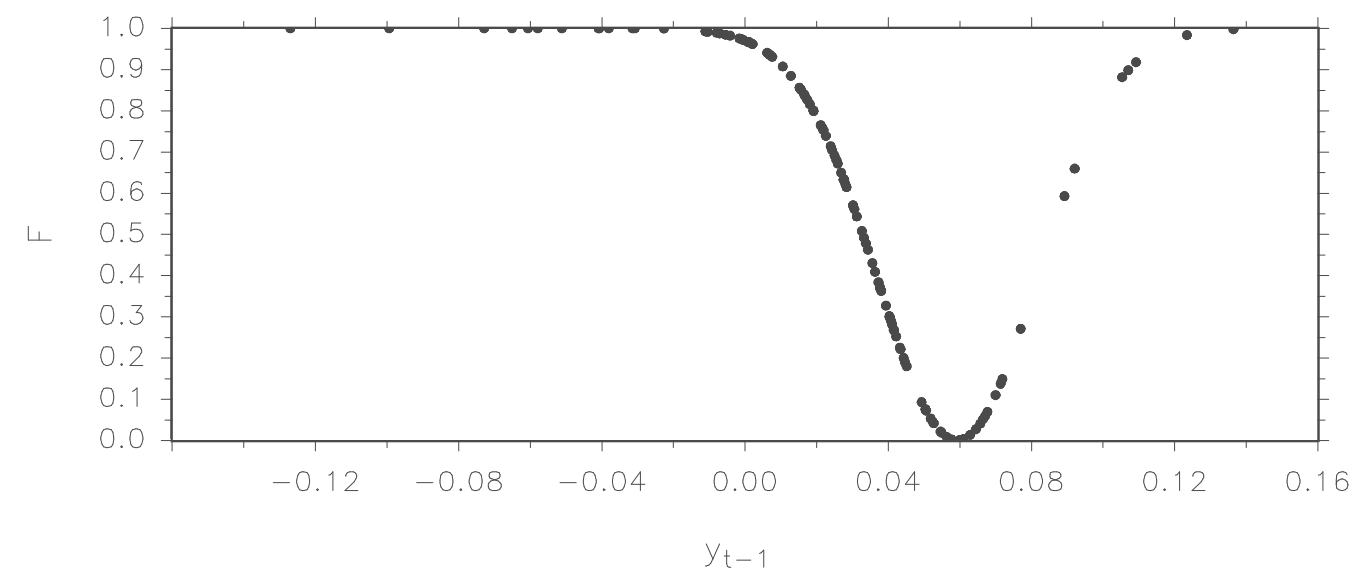

Fig. 4.22. Consumption (first difference of logarithm). Estimated transition function vs the transition variable. 


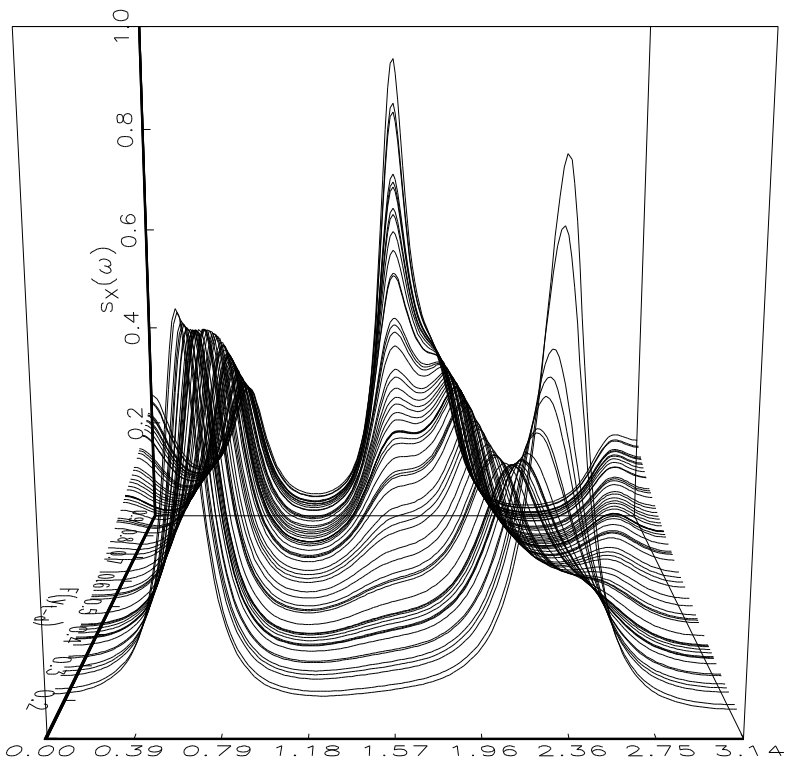

Fig. 4.23. Consumption (first difference of logarithm). 'Sliced' spectra.

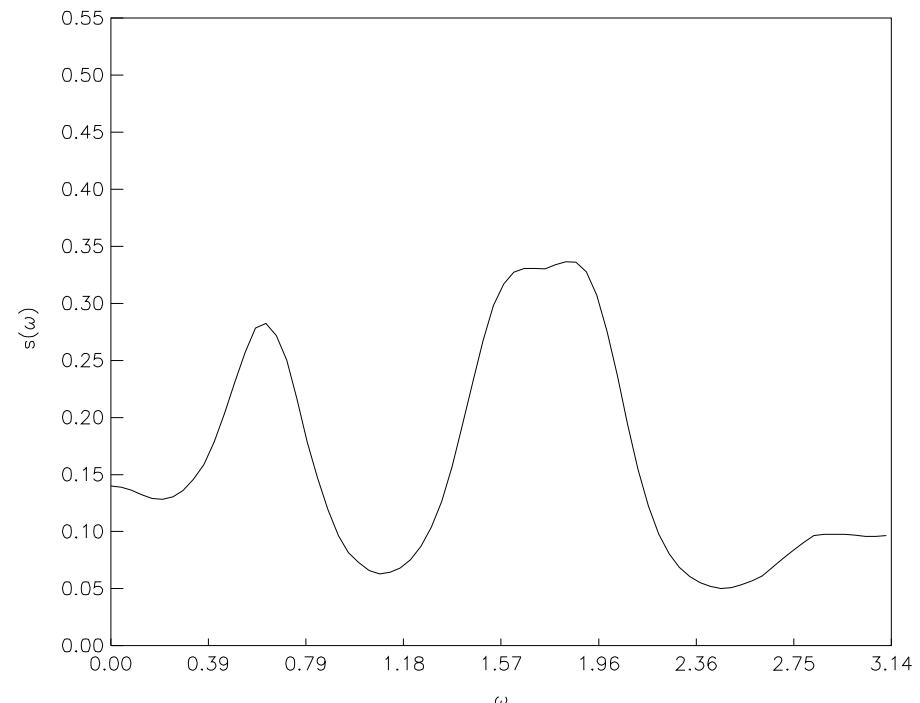

Fig. 4.24. Consumption (first difference of logarithm). Model spectrum. 


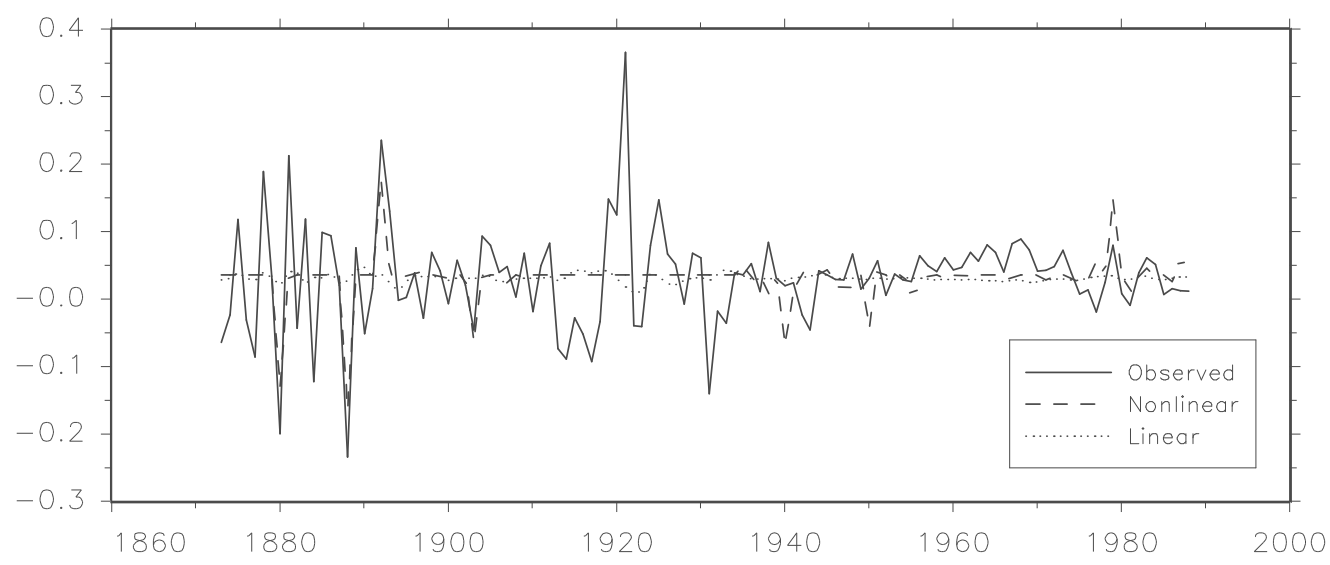

Fig. 4.25. Productivity (first difference of logarithm). Observed values, predictions from STAR model, and predictions from AR model.

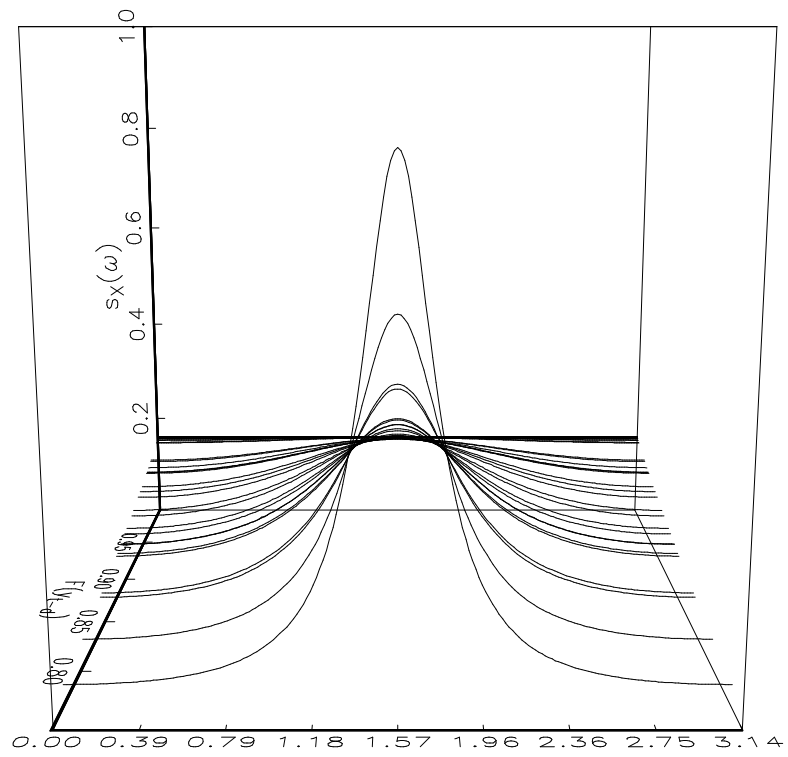

Fig. 4.26. Productivity (first difference of logarithm). 'Sliced' spectra. 


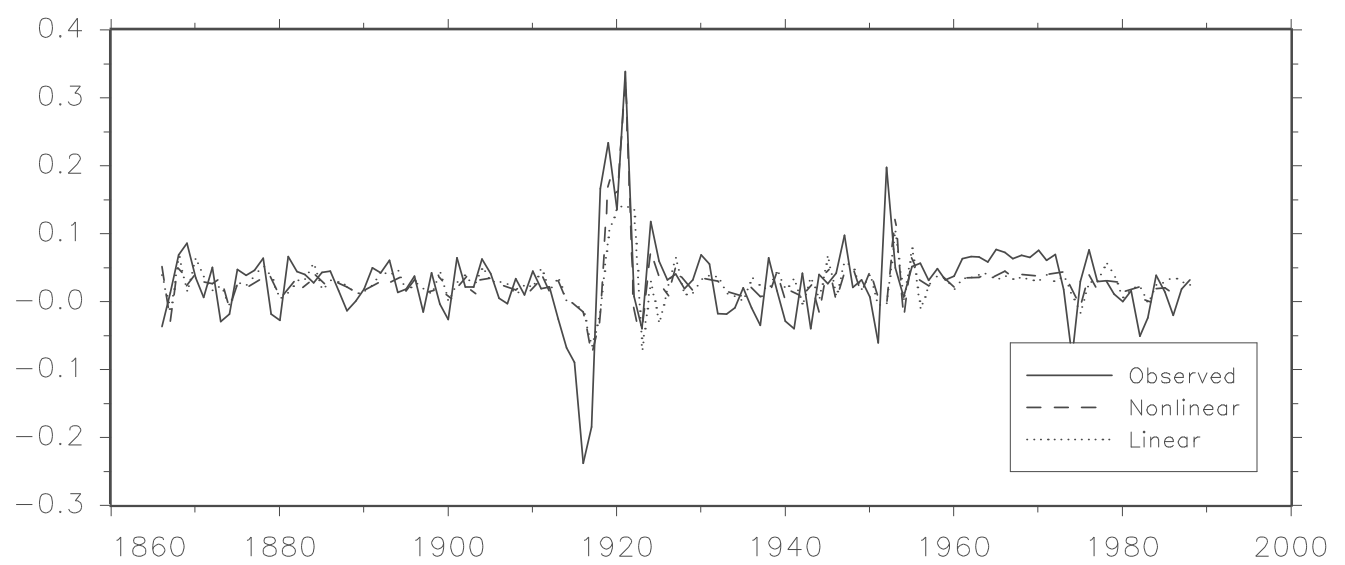

Fig. 4.27. Real wage (first difference of logarithm). Observed values, predictions from STAR model, and predictions from AR model.

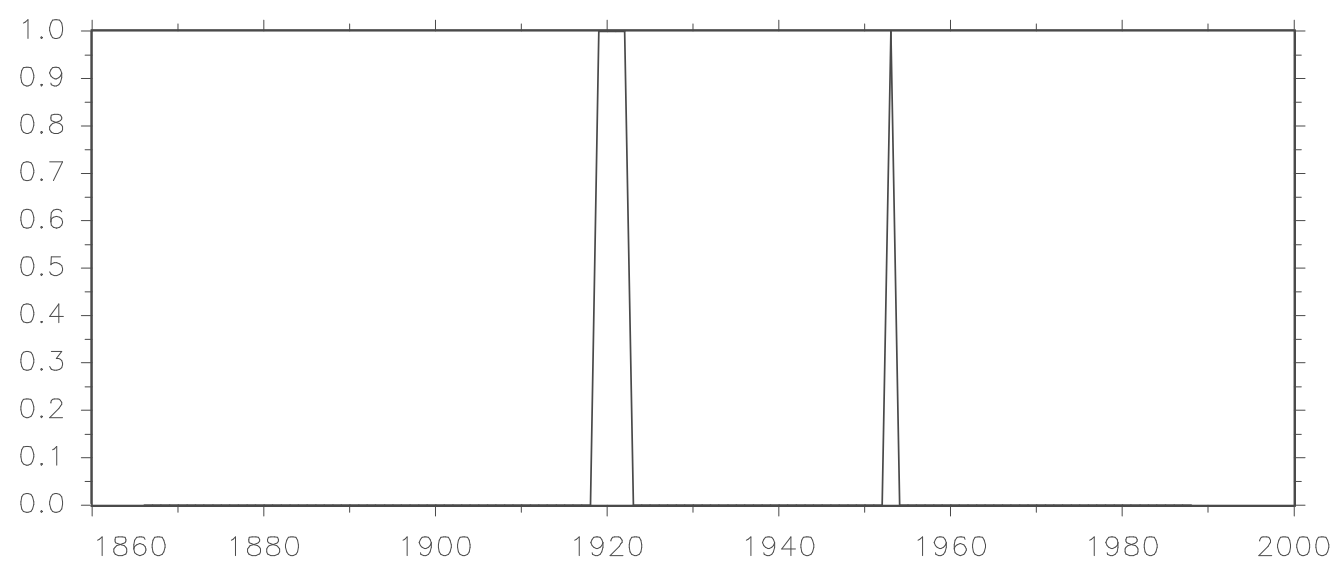

Fig. 4.28. Real wage (first difference of logarithm). Estimated transition function over time. 


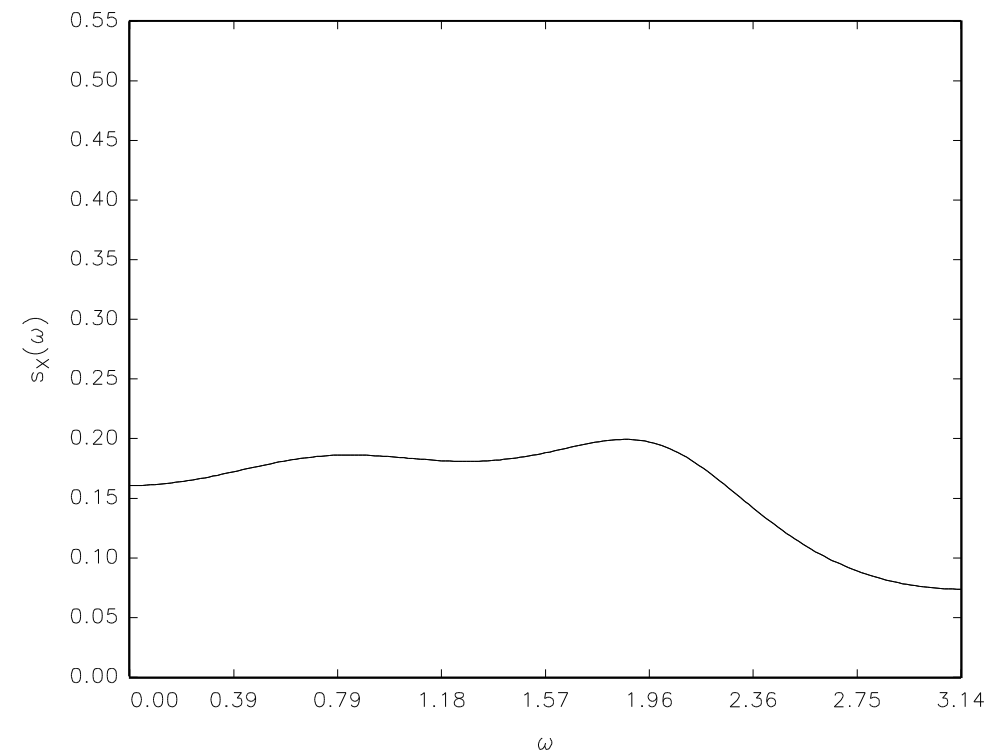

Fig. 4.29. GDP (first difference of logarithm). Model spectrum, AR(4) model.

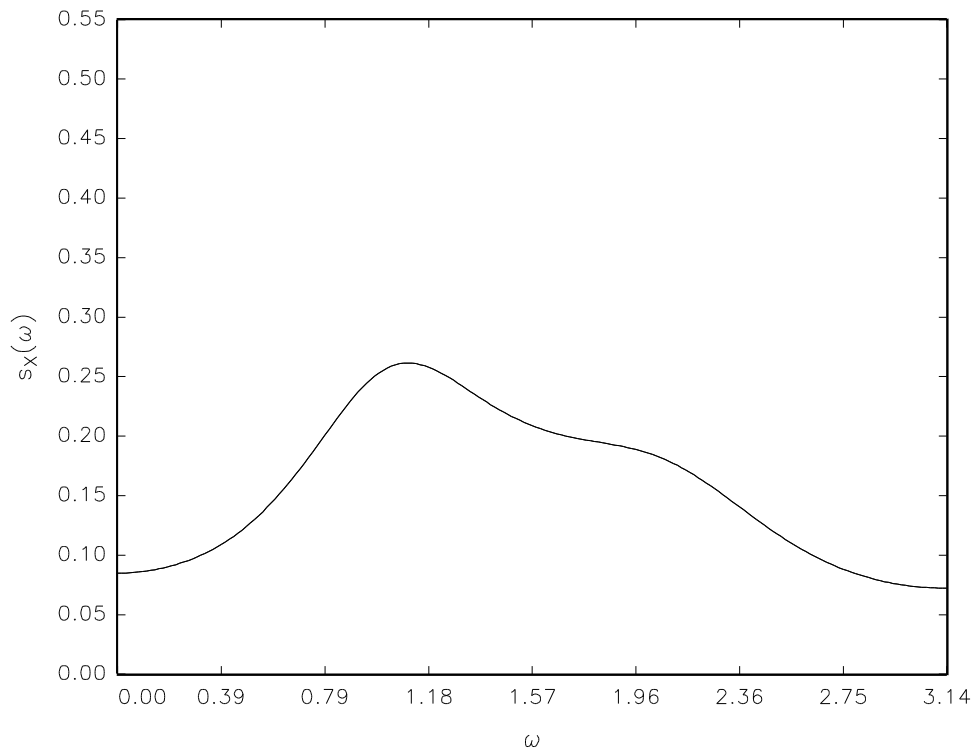

Fig. 4.30. Investments (first difference of logarithm). Model spectrum, AR(4) model. 